\title{
O Social Credit System na Era dos Dados
}

DOI: https://doi.org/10.22409/pragmatizes.v10i19.42516

\section{Fernanda Rito ${ }^{1}$ \\ Pedro Teixeira Gueiros ${ }^{2}$}

\begin{abstract}
Resumo: $O$ presente trabalho visa investigar o controverso sistema de crédito social chinês, denominado Social Credit System, e seus impactos na vida dos indivíduos. Para tanto, parte de breves considerações acerca da era dos dados e a espetacularização da vida, marcada pela supremacia do processamento de dados e sua transfiguração em sistemas sociopolíticos disruptivos de hipervigilância, verificados, inclusive, no Brasil. Conclui-se pela necessária valoração de um componente ético por meio do devido reconhecimento dos dados pessoais como direito humano fundamental.
\end{abstract}

Palavras-Chave: Social Credit System; dataísmo; capitalismo de vigilância; proteção de dados.

\section{El Social Credit System en la Era de los Datos}

Resumen: El presente trabajo tiene como objetivo investigar el controvertido sistema de crédito social chino, llamado Social Credit System, y sus impactos en la vida de las personas. Por lo tanto, comienza con breves consideraciones sobre la era de los datos y la espectacularización de la vida, marcada por la supremacía del procesamiento de datos y su transfiguración en sistemas sociopolíticos disruptivos de hipervigilancia, verificada, incluso en Brasil. Concluye con la valoración necesaria de un componente ético mediante el debido reconocimiento de los datos personales como un derecho humano fundamental.

Palabras clave: Social Credit System; dataismo; vigilancia del capitalismo; protección de datos.

\section{The Social Credit System in the Data Age}

Abstract: This present work aims to investigate the controversial Chinese social credit system, and its impacts onto individuals' lives. Therefore, it starts from brief considerations about the data age, marked by the supremacy of data processingand the spectacularization of life, and its transfiguration into disruptive hypervigilance sociopolitical systems, even found in Brazil. It is concluded by the

\footnotetext{
${ }^{1}$ Fernanda Paes Leme Peyneau Rito. Doutora em Direito Civil pela Universidade do Estado do Rio de Janeiro / UERJ. Professora Titular de Direito Civil do Ibmec/RJ, Brasil. E-mail: fernanda.rito@ibmec.edu.br - https://orcid.org/0000-0001-6909-2204

${ }^{2}$ Pedro Teixeira Gueiros Graduando em Direito pelo lbmec-RJ, Brasil. E-mail: pedrogueiros@uol.com.br - https://orcid.org/0000-0001-5885-420X
} 
necessary valuation of an ethical component through the proper recognition of personal data as a fundamental human right.

Keyword: Social Credit System; dataism;surveillance capitalism; data protection.

\section{O Social Credit System na Era dos Dados}

\section{Considerações iniciais: a era dos}

\section{dados e a espetacularização da vida}

A ficção já criou diversas sociedades futuristas, nas quais a tecnologia e a inteligência de dados são características primordiais de uma organização social vigilante, preditiva e ranqueadora dos cidadãos. Black Mirror,1984, Minority Report, Elysium, Divergente e O preço do amanhã são alguns exemplos de sociedades distópicas e com emprego de alta tecnologia.

Contemporaneamente, entanto, o distanciamento entre o que era ficção e a realidade vem diminuindo consideravelmente. Todos já se depararam com alguma situação para a qual a melhor definição era "black mirror". Assistentes pessoais virtuais; GPS; ofertas personalizadas; edição genética; híbridos humanos; implantação de chips em pessoas com o objetivo de melhoramento (transumanos), enfim, a realidade que se apresenta hoje está muito próxima da ficção de ontem.

Há de se perguntar como isso é possível e a resposta, necessariamente, perpassa dois aspectos: evolução tecnológica e a espetacularização da vida, mas, sobretudo, o ciclo vicioso estabelecido entre esses dois aspectos. A rigor, 0 sistema de crédito social chinês, objeto de análise, está inserido em um contexto histórico muito mais abrangente e de escala mundial, identificado como dataísmo ${ }^{3}$ : momento inédito na civilização humana, em que a crença e o uso desenfreado de

\footnotetext{
${ }^{3} \mathrm{O}$ termo foi cunhado originalmente pelo jornalista David Brooks ao descrever a capacidade dos dados determinarem cada vez mais os padrões e comportamentos humanos, interferindo na capacidade de tomada de decisões (2013). Para o historiador Yuval Noah Harari, "o Universo consiste num fluxo de dados e o valor de qualquer fenômeno ou entidade é determinado por sua contribuição ao processamento de dados" (2016, p. 399). Nesse sentido, "dataísmo" é entendido como o fenômeno caracterizado pela supervalorização dos dados produzidos e comercializados, sobretudo, em ambientes virtuais.
} 


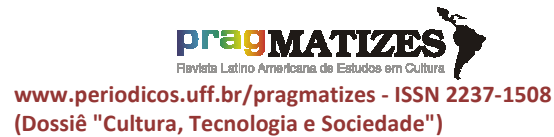

(Dossiê "Cultura, Tecnologia e Sociedade") dados definem o estágio antropológico contemporâneo.

O dataísmo, por sua vez, foi potencializado por uma mudança comportamental anterior: a espetacularização da vida e publicização daquilo que, tradicionalmente, era mantido na esfera privada e até íntima. As facilitações prometidas pelos diversos usos da internet e, principalmente, a alteração nas formas de interação social medidas por plataformas, acompanhadas da naturalização do compartilhamento de dados e informações pessoais, possibilitaram a coleta de um sem número de informações pessoais, etapa imprescindível e necessária para o desenvolvimento das diversas aplicações existentes hoje, tal como o sistema de crédito social chinês.

É possível dizer que, desde as revoluções burguesas em meados do séc. XVII, vigorou o culto ao humanismo, marcado pelo valor supremo da vida humana, em que o ser humano passa a ser visto como o mais avançado sistema capaz de processar dados ou informações. Atualmente, no entanto, com 0 desenvolvimento da internet, viu-se a emersão dos dados como um novo valor inestimável, fruto do avanço tecnológico e do desenvolvimento das inteligências artificiais.

Destarte, a humanidade vem depositando suas identidades, capacidades e habilidades em algoritmos externos ${ }^{4}$, dotados de inteligência avançada, com o fito de facilitar e promover a qualidade de vida $^{5}$. O propósito inicial parece, de fato, nobre. "Nunca a humanidade viveu tão bem", conforme indicam os "dados"6 e, tal fato, é facilmente constatável desde a substituição das atividades mecânicas humanas, fruto das Revoluções Industriais ${ }^{7}$.

\footnotetext{
${ }^{4}$ Algoritmos externos podem ser entendidos como conjunto de raciocínios lógicos artificialmente concebidos. (SOLON, 2019).

${ }^{5}$ Nesse sentido, ao conceituar o processo do "dataísmo", explicita Yuval Noah Harari que "O trabalho de processamento de dados deveria, portanto, ser confiado a algoritmos eletrônicos, cuja capacidade excede muito a do cérebro humano. Na prática, os dataístas são céticos no que diz respeito ao conhecimento e à sabedoria humanos, e preferem depositar sua confiança em megadados e em algoritmos computacionais". (2016, p. 400).

${ }^{6}$ Max Roser, de 34 anos, defende, com dados e gráficos, a tese de que nunca a humanidade viveu tão bem como hoje em dia. Roser argumenta que, se olharmos para os últimos 200 anos, temos vários motivos para estarmos bastante otimistas com os rumos que tomamos (ORENSTEIN, 2019).

${ }^{7}$ Antes da Revolução Industrial, o mercado de energia humano dependida quase exclusivamente das plantas. As pessoas viviam diante de um reservatório de energia
} 


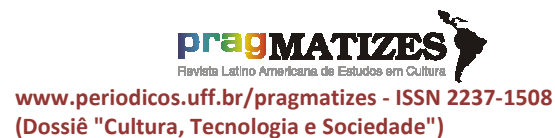
(Dossiê "Cultura, Tecnologia e Sociedade")
$O$ que se verifica na contemporaneidade, entretanto, é algo sem precedentes. Trata-se não apenas do desenvolvimento de inteligências artificiais próximas ao raciocínio cognitivo humano ${ }^{8}$, mas de uma efetiva transferência da autonomia dos indivíduos à autoridade algorítmica externa. Porquanto, as inteligências artificiais se apresentam tão poderosas às elucidações da natureza humana, que o próprio indivíduo corre o grande risco de se tornar insignificante, consoante a profecia de Frankenstein ${ }^{9}$.

verde carregando 3 mil hexajoules por ano e tentavam extrair o máximo possível dessa energia. Mas havia um claro limite à quantidade que podia ser extraída. Durante a Revolução Industrial, passamos a perceber que na verdade estamos vivendo ao lado de um oceano enorme de energia, que contém bilhões e mais bilhões de hexajoules de energia em potencial. Tudo que precisamos fazer é inventar geradores melhores (HARARI, 2016, p. 349-350).

${ }^{8} \mathrm{Há}$ quem diga que os microprocessadores quânticos são difíceis de controlar e que se demonstrará que a Lei de Moore, que diz que a cada dois anos o poder de cálculo dobra, está errada porque os chips enfrentarão barreiras físicas intransponíveis. Eu, no entanto, acredito que surgirão novas propostas tecnológicas e considero viável que a capacidade de computação do cérebro possa ser replicada em um tempo razoável (ADALMA, apud ABBEEL, 2019)

${ }^{9} \mathrm{O}$ mito do Frankenstein confronta o Homo sapiens com o fato de que os últimos dias estão se aproximando depressa. A não ser que alguma catástrofe nuclear ou ecológica intervenha, diz a história, o ritmo do desenvolvimento tecnológico logo levará à
Deter informação, assim como o conhecimento de uma maneira geral, sempre esteve relacionado a poder ${ }^{10}$. No atual estágio do desenvolvimento tecnológico, para maximizar o poder associado à capacidade de lucrar e impor valores em uma sociedade, torna-se cada vez mais imprescindível angariar e controlar o maior número possível de informações sobre todos os indivíduos, grupos e organizações. O controle sobre dados privados é a melhor expressão desse tipo de dominação. $\mathrm{Na}$ atualidade, as

substituição do Homo sapiens por seres completamente diferentes que têm não só uma psique diferente como também mundos cognitivos e emocionais muito diferentes. Isso é algo que maioria dos sapiens considera extremamente desconcertante (HARARI, 2016, p. 423).

${ }^{10}$ Ainda no século XIX, Alexis de Tocqueviile já constatava que a liberdade de imprensa, com sua função de fazer circular a informação, era um dos pilares do sucesso da democracia estadunidense: "Reduzida a esses únicos recursos, a imprensa ainda exerce um imenso poder na América. Ela faz circular a vida política em todas as porções desse vasto território. É ela cujo olho sempre aberto põe incessantemente a nu os mecanismos secretos da política e força os homens públicos a comparecer sucessivamente diante do tribunal da opinião. É ela que agrupa os interesses em torno de certas doutrinas e formula o símbolo dos partidos; é por ela que estes se falam sem se ver, se ouvem sem ser postos em contato. Quando um grande número de órgãos da imprensa consegue caminhar no mesmo sentido, sua influência se torna, com o tempo, quase irresistível, e a opinião pública, atingida sempre do mesmo lado, acaba cedendo a seus golpes" (2005, p. 214). 
empresas perceberam que as pessoas estavam muito interessadas em compartilhar suas próprias informações e constataram que era possível lucrar em cima de tais trocas sociais (SNOWDEN, 2019, p. 10).

Essa necessidade de compartilhar experiências é o traço marcante da espetacularização da vida. Em uma sociedade espetacularizada $^{11}$, pessoas criam cenários de vida perfeitos e contam suas histórias da forma como idealizam. Recortam e divulgam o que querem compartilhar, claro. $\mathrm{A}$ experiência só alcança o seu patamar máximo se compartilhado $^{12}$. Essa

\footnotetext{
${ }^{11} \mathrm{O}$ conceito de "sociedade do espetáculo" foi estabelecido pela primeira vez por Guy Debord na França, antes das revoltas de maio de 1968. Segundo o autor, "o espetáculo é ao mesmo tempo parte da sociedade, a própria sociedade e seu instrumento de unificação. Enquanto parte da sociedade, o espetáculo concentra todo o olhar e toda a consciência. Por ser algo separado, ele é o foco do olhar iludido e da falsa consciência; a unificação que realiza não é outra coisa senão a linguagem oficial da separação generalizada" (DEBORD, 1997, p. 14)

${ }^{12}$ Os dataístas acreditam que experiências não têm valor se não forem compartilhadas e que não precisamos - na verdade não podemos encontrar significado em nosso interior. Só precisamos gravar e conectar nossa experiência ao grande fluxo de dados, e os algoritmos vão descobrir seu significado e nos dizer o que fazer. Vinte anos atrás, turistas japoneses eram o motivo de riso universal porque levavam consigo câmeras e tiravam fotos de tudo o que estava à vista. Hoje todos fazem isso. Se você for à Índia e deparar com
}

necessidade de compartilhamento da vida, por si só, já é preocupante, pois, necessariamente resulta na divulgação de diversas informações pessoais, além de possíveis consequências na saúde, sobretudo psicológica. Agravase ainda mais porque, ao fazerem isso, as pessoas se transportam para uma ficção autocriada, na qual se sentem mais seguras e acabam revelando ainda mais informações.

Essa alteração comportamental associada ao desenvolvimento tecnológico sedimenta o capitalismo de vigilância, espécie de modus vivendi de índole digital. Nesse sentido, imperioso registrar que, no âmbito das relações travadas entre indivíduos e empresas de tecnologia, os serviços prestados por estas não são gratuitos. Trata-se de um verdadeiro trade off, ao qual ao participarem das redes virtuais, os

um elefante, você não vai olhar para o animal e se perguntar "O que estou sentindo?" - você estará ocupado demais pegando seu smartphone, tirando uma foto do elefante, postando-a no Facebook, e depois conferindo sua conta a cada dois minutos para ver quantas curtidas obteve. Manter um diário particular - prática humanista comum em gerações anteriores - parece, para os jovens de hoje, ser algo totalmente fora de propósito. Para que escrever alguma coisa que mais ninguém vai ler? O novo lema é: "Se você experimentar algo - grave. Se gravar algo faça upload. Se fizer upload de algo compartilhe" (HARARI, 2016, p. 419). 
RITO, Fernanda; GUEIROS, Pedro Teixeira. O Social Credit System na Era dos Dados. PragMATIZES - Revista Latino-Americana de Estudos em Cultura, Niterói/RJ, Ano 10, n. 19, p. 170-213, set. 2020.

indivíduos cedem seus dados pessoais às redes sociais e demais meios de comunicação online, que lucram por meio de remuneração indireta como propagandas e comercialização dos dados pessoais obtidos. Assim, a relação travada parece gratuita, mas há efetiva prestação de serviço por meio de remuneração indireta, consoante o disposto na legislação consumerista $^{13}$, relação esta já reconhecida pelo $S T J^{14}$.

\footnotetext{
${ }^{13}$ Art. $3^{\circ}$, do Código de Defesa do Consumidor (Lei no 8.078/90): Fornecedor é toda pessoa física ou jurídica, pública ou privada, nacional ou estrangeira, bem como os entes despersonalizados, que desenvolvem atividade de produção, montagem, criação, construção, transformação, importação, exportação, distribuição ou comercialização de produtos ou prestação de serviços. $\S 2^{\circ}$ Serviço é qualquer atividade fornecida no mercado de consumo, mediante remuneração, inclusive as de natureza bancária, financeira, de crédito e securitária, salvo as decorrentes das relações de caráter trabalhista (BRASIL, 1990).

${ }^{14}$ CIVIL E CONSUMIDOR. INTERNET. RELAÇÃO DE CONSUMO. INCIDÉNCIA DO CDC.GRATUIDADE DO SERVIÇO. INDIFERENÇA. PROVEDOR DE PESQUISA VOLTADA AO COMÉRCIO

ELETRÔNICO.INTERMEDIAÇÃO.

AUSÊNCIA. FORNECEDOR. NÃO

CONFIGURADO.1. Ação ajuizada em 17/09/2007. Recurso especial interposto em 28/10/2013 e distribuído a este Gabinete em 26/08/2016.2. A exploração comercial da Internet sujeita as relações de consumo daí advindas à Lei no 8.078/90.3. O fato de o serviço prestado pelo provedor de serviço de Internet ser gratuito não desvirtua a relação de consumo.4. Existência de múltiplas formas de atuação no comércio eletrônico.5. O provedor de buscas de produtos que não realiza qualquer intermediação entre consumidor e
}

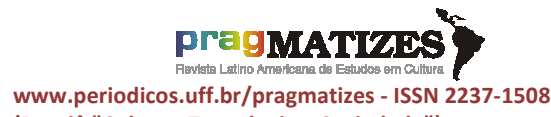

(Dossiê "Cultura, Tecnologia e Sociedade")
À frente de fatores como a consolidação de uma sociedade de massa, o aumento exponencial das produções, o consumo de bens e serviços e um rápido desenvolvimento tecnológico, chega-se a um ambiente em que novos produtos e serviços utilizam os dados pessoais como principal insumo de suas atividades (MULHOLLAND, 2019, p. 107). Refere-se a uma valiosa massa de informações, já denominada como "novo petróleo", numa alusão a sua crescente expressão econômica e mercadológica. Não à toa, das dez marcas mais valiosas do mundo, nove são empresas que utilizam dados pessoais como principal commodity ${ }^{15}$. Uma vez compilados e cruzados, os dados são capazes de revelar padrões, tendências e associações

vendedor não pode ser responsabilizado por qualquer vício da mercadoria ou inadimplemento contratual.6. Recurso especial provido (STJ, 2016).

${ }^{15}$ De acordo com o ranking de 2020, as marcas mais valiosas do mundo são: 1) Amazon: US\$221bilhões (varejo); 2) Google: US\$ 160 bilhões (tecnologia); 3) Apple: US\$ 141 bilhões (tecnologia); 4) Microsoft: US\$ 117 bilhões (tecnologia); 5) Samsung: US\$ 94 bilhões (tecnologia); 6) ICBC: US $\$ 81$ bilhões (financeiro); 7) Facebook: US\$ 80 bilhões (mídia); 8) Walmart: US $\$ 78$ bilhões (varejo); 9) PingAn: US $\$ 69$ bilhões (seguros); 10) Huawei: US $\$ 65$ bilhões (tecnologia) (FIGO, 2020). 
relativas ao comportamento humano. Tem-se a monetização do big data ${ }^{16}$.

Nesse sentido, como possuem

uma alta expressão econômica, os

metadados $^{17}$ são facilmente

comercializados em diversos

segmentos do mercado que

necessitam de um conhecimento e

perfil estratégico para perseguir sua finalidade econômica ${ }^{18}$. Ocorre que, antes de adquirirem qualquer viés patrimonial, tais dados são essencialmente inerentes à dignidade, privacidade e liberdade da pessoa humana. Observa-se que 0 atual enriquecimento tecnológico se deflagra

\footnotetext{
${ }^{16}$ Termo de origem anglófona para denominar a análise e a interpretação de grandes volumes de dados de grande variedade. Seus principais aspectos são definidos por " $5 \mathrm{Vs":}$ Volume, Variedade, Velocidade, Veracidade e Valor (HELDER, 2018).

17 (...) metadados são dados sobre dados. Mais exatamente, são dados feitos por dados - um punhado de tags e marcadores que permitem que os dados sejam úteis. A maneira mais direta de pensar nos metadados, no entanto, é como dados de atividade: todos os registros de tudo que você faz em seus dispositivos eletrônicos e tudo que eles fazem por conta própria (SNOWDEN, 2019, p. 156).

${ }^{18}$ Acerca da rentabilidade das empresas de tecnologia sobre dados pessoais, é possível perceber duas fases principais. Em primeiro lugar, visa-se alcançar uma massa crítica de usuários e, posteriormente, parte-se para a exploração e a monetização da rede social, por meio da venda de espaços para a publicidade, da comercialização de produtos (como publicações patrocinadas) e da "venda" de perfis, cadastros e dados pessoais de seus usuários (TEFFÉ; BODIN DE MORAES, 2017, p. 122).
}

na medida do empobrecimento humano, dada à relativização de sua autodeterminação. Tem-se a disrupção do projeto inicial das inteligências artificiais, de facilitador da vida humana, para atendimento de propósitos capitalistas de vigilância, onde a pessoa humana se insere em uma posição abstratamente considerada $^{19}$.

A coleta massiva e inteligente de dados, outrossim, não se limita aos ambientes virtuais. Outro espaço que também se revela um agente

\footnotetext{
${ }^{19}$ Ciência e tecnologia não abrem somente espaços de liberdade, podendo assim liberar constrições naturais e culturais. Dão início também a processos de expropriação, de redução dramática da liberdade de escolha, que podem ser combatidos exaltando ao máximo as potencialidades da autodeterminação. Não quero aqui insistir sobre as tecnologias do controle. Quero assinalar aquela que chamarei a entrega da pessoa à sociedade do algoritmo. Refletindo sobre a última crise financeira, colocou-se em evidência como muitas decisões sobre os investimentos foram confiadas a algoritmos elaborados por matemáticos e físicos. Uma das potências que governam o mundo, o Google, foi construída com base em um algoritmo que decide sobre coleta, seleção e apresentação das informações. Algoritmos são cada vez mais a base da ininterrupta produção de perfis individuais, familiares, de grupo, que se tornaram elemento constitutivo da sociedade de classificação e que produzem novas hierarquias sociais. A própria construção da identidade é subtraída da consciência da pessoa e confiada ao automatic computing. A pessoa, de novo entregue à abstração, desencarnada, reduzida a um fantasma tecnológico? (RODOTÁ, 2018, p. 152)
} 
"minerador" de dados são os espaços físicos públicos ${ }^{20}$. Atualmente, em meio às medidas de contenção da pandemia do novo coronavírus, a vulgarização do uso dos dados pessoais, inclusive, sensíveis por meio, por exemplo, de câmeras de vigilância e aparelhos de geolocalização, ameaçam direitos fundamentais à privacidade $e$ às liberdades civis mundo afora, conforme aponta Chiara de Teffé ${ }^{21}$.

\footnotetext{
${ }^{20} \mathrm{O}$ barateamento da tecnologia e a consequente popularização desses equipamentos tornaram quase impossível circular por espaços urbanos sem ser alvo das câmeras em algum momento. As novas tecnologias digitais de processamento de imagem potencializam práticas de identificação. O uso disseminado e descontrolado interfere na administração de espaços públicos pela intensificação do policiamento preventivo, permitindo abusos ligados ao chamado racial profiling e à gentrificação (EVANGELISTA, 2018, p. 397).
}

${ }^{21}$ Alguns exemplos - replicados em vários países - de aplicação de tecnologias de controle e vigilância para a contenção da doença são: aplicativos que usam sinais de Bluetooth entre celulares para verificar se possíveis portadores do coronavírus estão em contato próximo com outras pessoas (Cingapura); análises de transações com cartões de crédito, de dados de localização e conversas para rastrear casos confirmados e informar às pessoas se elas chegaram perto de um portador de coronavírus (Coréia do Sul); na Índia, carimbos nas mãos de pessoas suspeitas de ter a doença e rastreamento a partir de seus celulares e dados pessoais, de forma a reforçar as quarentenas; diálogo entre governo e empresas de tecnologia sobre a possibilidade de usar dados de localização e movimentação dos smartphones (EUA); empresa de telecomunicações usando dados de localização geográfica do cartão SIM para
Nesse contexto específico e com peculiaridades e objetivos próprios, vem sendo desenvolvido desde 2014 o sistema de crédito social chinês - Social Credit System (SCS) -, objeto da análise aqui proposta. Em síntese, trata-se de um sistema que ranqueia e classifica os cidadãos em razão de hábitos e comportamentos, utilizando alta tecnologia e massiva coleta e tratamento de dados.

Importante frisar que não se trata de uma invenção chinesa ou de uma iniciativa única, ao contrário, o ranqueamento e a utilização de dados pessoais é uma realidade em diversas sociedades. No Brasil, por exemplo, temos os cadastros de bons e maus pagadores, de dados de saúde por planos, operadoras e estabelecimentos de saúde e de usuários dos mais diversos serviços por aplicativos.

No entanto, o modelo chinês vem causando preocupações por parte da comunidade global, vez que o cenário deflagrado na China é fruto da

se comunicar com as autoridades quando mais de vinte telefones forem detectados em uma área de cem metros quadrados (Suíça); uso massivo de reconhecimento facial para identificar quem está violando a quarentena (Rússia); e uso de drones para vigiar os cidadãos e impedir reuniões ao ar livre em locais na China (2020). 


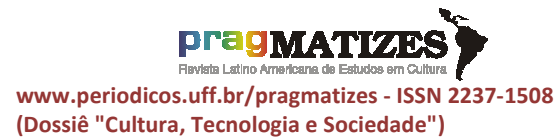

(Dossiê "Cultura, Tecnologia e Sociedade") confluência de um Estado historicamente marcado por sua opressão e controle social com uma nova era de supervalorização dos dados, denominada por alguns cientistas sociais como "dataísmo". Consequentemente, embora haja muitas indefinições quanto à identidade da realidade chinesa que vem sendo delineada, é possível constatar elementos quanto à sua funcionalidade $e$ as consequências suportadas por indivíduos, tendo em vista, dentre outras coisas, que a existência de leis próprias de regulamentação da internet e do uso de dados pessoais na China demonstra-se ineficaz diante da imposição de um capitalismo de vigilância. Indubitavelmente, a eficácia na adoção de tamanhos mecanismos de vigilância e controle em massa impacta todos os aspectos da vida das pessoas.

Nesse sentido, o presente artigo apresenta um estudo do modelo de crédito social chinês, de modo a identificar seu funcionamento sistêmico. Com base na bibliografia sobre o tema, procedeu-se à coleta e análise das informações e medidas do governo central chinês, incluindo a realização de entrevista com uma cidadã chinesa a respeito da experiência de viver sob o sistema mais avançado de controle de dados pessoais já operante no mundo. Para a compreensão do Social Credit System, o estudo foi subdividido em três pontos centrais: a coleta e unificação de dados; a elaboração das listas de classificação, "negra" e "vermelha"; e a concretização de um sistema de recompensas e punições. Em seguida, comparam-se as realidades chinesa e brasileira diante da era dos dados, demonstrando que ambos os países compartilham um mesmo movimento no sentido da existência de uma forte cultura de desvalorização dos dados pessoais e consequente proposição de medidas que ameaçam o direito à privacidade $\mathrm{e}$ à proteção de dados pessoais. Apresentam-se considerações finais no sentido de alertar sociedade civil e governantes para a urgência da valoração de um componente ético no desenvolvimento tecnológico e algorítmico, funcionalizado aos valores fundamentais de uma sociedade, tais como a igualdade, a liberdade, a solidariedade e a dignidade da pessoa humana. 


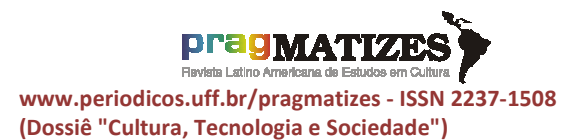

(Dossiê "Cultura, Tecnologia e Sociedade")

\section{O Social Credit System (SCS)}

O SCS é um sistema criado e em desenvolvimento na China com o objetivo de medir a credibilidade de cidadãos e empresas, a partir da atribuição de avaliações recíprocas representativas da confiança que despertam em razão dos seus comportamentos. O programa foi iniciado em 2014 de forma facultativa e se tornará, segundo as autoridades, compulsório no ano corrente para os quase um 1,4bilhões de chineses ${ }^{22}$.

Conforme o documento oficial de lançamento do programa, o SCS é parte integrante do sistema econômico e de governança da China. A justificativa para a implementação do programa seria "Promover a construção de um sistema de crédito social de maneira abrangente, um meio eficaz para melhorar a integridade social, promover a confiança mútua social e reduzir as contradições sociais" (CHINA, 2014).

A leitura do documento evidencia a adoção da racionalidade econômica como premissa para a construção e justificação do sistema. De pronto, o problema que se

\footnotetext{
${ }^{22}$ Conforme dados estatísticos de 2018 do Banco Mundial (BANCO MUNDIAL, 2020).
}

identifica é justamente uma inversão valorativa: as pessoas e os seus dados pessoais são instrumentalizados para a construção de um sistema de crédito eficiente quando, em nosso entendimento, o sistema de crédito deveria ser instrumento de promoção e melhora da condição de vida das pessoas.

Não se discute que um bom sistema de crédito, com redução de custos de transação e facilitação de acesso traz benefícios para a população em geral. Entretanto, há de se questionar se o trade off que está sendo imposto é realmente benéfico e condizente com um modelo social pretendido. Afinal, as pessoas estão sendo transformadas em dados, que uma vez coletados, tratados, combinados e compartilhados de diferentes formas, as classificam e condicionam o exercício de direitos e interações sociais. A título de exemplo, diversos canais de comunicação noticiaram que mais de 20 milhões de chineses foram impedidos de viajar em 2019 em razão de sua baixa classificação no $S C S^{23}$.

${ }^{23}$ Conforme as informações publicadas, cerca de 17,5 milhões de passagens áreas foram canceladas e 5,5 milhões de assentos de trens recusados, com base na Lista Negra de 


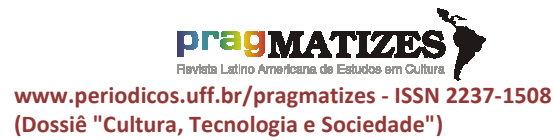

O projeto foi iniciado em 2014 e em sua fase final de implementação ficou estruturado em três etapas: coleta e unificação de dados; elaboração das listas de classificação, negra e vermelha; e concretização de um sistema de recompensas e punições.

A primeira etapa consiste na coleta descentralizada dos dados por todas as esferas e autoridades administrativas, com apoio e participação direta da iniciativa privada para posterior consolidação em um banco único, a Plataforma Nacional de Compartilhamento de Informações sobre Crédito - $N C I S P^{24}$, instituída pela Comissão Nacional de

Desenvolvimento e Reforma $N D R C^{25}$, principal responsável pela implementação do SCS. A Plataforma Nacional de Compartilhamento de Informações sobre Crédito, caracterizada como a "espinha dorsal" do sistema, efetivamente funciona

Infratores, mantida pelo Supremo Tribunal Popular (MCDONALD, 2019); (RFI, 2020); (REISINGER, 2019).

\footnotetext{
${ }^{24}$ Tradução livre para National Credit Information Sharing Platform (CREDIT CHINA, 2019).

${ }^{25}$ Tradução livre para National Development and Reform Commission (PEOPLE'S

REPUBLIC OF CHINA, 2014).
}

como a base central dos dados (MEISSNER, 2017).

Como já referido, no sistema de crédito social chinês são coletados dados de pessoas e de empresas. A título de exemplificação, as principais categorias de dados de pessoas coletados e consolidados na NCISP são: informações de identidade e emprego; informação financeira; histórico jurídico e processual; infrações regulatórias e legais; comportamento cívico; prêmios e conquistas; e dados políticos. Sobre as empresas, as principais categorias de dados coletados e consolidados são: informações básicas de identificação; informações de pessoal e representação da empresa; informações financeiras; licenças e qualificações; registros de infrações legais e administrativas; prêmios e menções; registros de propriedade intelectual e dados políticos. Importante destacar que os dados das empresas abrangem não apenas as chinesas, mas também as estrangeiras que fazem negócios na China.

Na verdade, o governo chinês já possui muitos dados das pessoas e das empresas e, não obstante a continuidade da coleta, essa etapa 


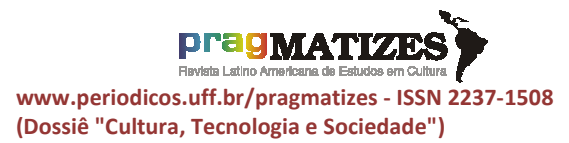

(Dossiê "Cultura, Tecnologia e Sociedade") inicial objetiva principalmente a consolidação e a unificação das informações. Consequentemente, o governo central chinês passou a desempenhar um papel de "possuidor dos dados registrados", cuja finalidade é consolidar em arquivos governamentais uma base de dados central das pontuações de crédito social coletadas por entidades participantes do sistema.

Através de tal base única e centralizada, o governo chinês disponibiliza a agências estatais, autoridades locais, bancos, grupos industriais e, inclusive, ao público em geral, os dados dos indivíduos e de companhias para que estes possam fazer suas próprias listas, a partir de seus próprios critérios. Nesse sentido, deve-se questionar se, ao revés da proposta originalmente concebida pelo governo chinês (de que o SCS seria um mecanismo de pontuação de cidadãos e companhias com base em seus comportamentos), a melhor definição do sistema de crédito social chinês não seria a de um massivo serviço de compartilhamento de dados sob controle do Estado, uma vez que só ele é o detentor da totalidade das informações.
Desse cenário de imenso compartilhamento e armazenamento de dados, deriva o segundo elemento norteador do SCS ou a segunda etapa do programa: a criação das "Listas Negras"26 e das "Listas Vermelhas". A proposta do governo central é utilizar tais listas para punir pessoas que não cumprem determinações legais. No entanto, a utilização das "Listas Negras" é bastante complexa. Elas não são gerenciadas e definidas pelo governo central, uma vez que cada órgão governamental local é responsável pela elaboração de suas próprias "Listas" atendendo à finalidade que deseja coibir" ${ }^{27}$. A "Lista Negra" mais conhecida é a "Lista Negra dos Infratores"28, mantida pelo Supremo Tribunal Popular, a Corte

\footnotetext{
${ }^{26}$ Tradução livre de black list (SOCIAL CREDIT WATCH, 2019). Merece crítica o uso do termo "preto" ou "negro" para adjetivar essa modalidade de lista, tendo em vista a imputação negativa a um atributo de cor, factível de ser associado à uma raça, caracterizando a identidade de um grupo ou população.

${ }^{27}$ Dentre as condutas mais comuns quanto à entrada em Listas Negras, destacam-se: o não cumprimento de obrigações civis; não pagamento de impostos; pôr em risco à segurança de passageiros em transportes etc. (SOCIAL CREDIT WATCH, 2019).

${ }^{28}$ Consoante sítio eletrônico do Tribunal em se mantém a "Rede aberta de informações executivas da China" (SUPREMO TRIBUNAL POPULAR, 2019).
} 
mais alta no país ${ }^{29}$, como mecanismo de coerção direcionado aos processos judiciais de execução em curso ${ }^{30}$.

Paralelamente às "Listas
Negras", existem as "Listas

Vermelhas"31. Estas, por sua vez, correspondem a menções honrosas atribuídas a cidadãos e companhias considerados exemplares e tomados como referência de boa reputação ${ }^{32}$. Cumpre ressaltar que as duas "Listas", elaboradas pelas respectivas autoridades locais, são nacionalmente divulgadas e disponibilizadas pelo

\footnotetext{
${ }^{29} \mathrm{O}$ presidente do Supremo Tribunal Popular da China explicou que o Sistema Judiciário chinês é composto pelo Supremo Tribunal Popular; pelos Tribunais do Povo, que são divididos em três instâncias (básica, intermediária e superior); e pelos Tribunais Especiais do Povo, que têm competências específicas, como os militares e marítimos (STF, 2009).
}

${ }^{30}$ Dentre os mecanismos de restrição impostas pela Corte, destacam-se: proibição de viajar em primeira classe nos transportes ferroviários, aéreos e marítimos; vedação a "consumos sofisticados" em hotéis, clubes e boates; compra e imóveis em construção e sofisticados; viajar nas férias; matricular filhos em escolas de alto padrão; restrições quanto locação de escritórios e hotéis. (THE SUPREME PEOPLE'S COURT OF THE PEOPLE'S REPUBLIC OF CHINA, 2019).

\footnotetext{
${ }^{31}$ Tradução livre para Red lists (SOCIAL CREDIT WATCH, 2019).

${ }^{32}$ Manutenção de relações harmoniosas em ambientes de trabalho, bom histórico em pagamento de seguros, boa situação de créditos financeiros, desenvolvimento de produtos inovadores, participação ativa em caridades, proteção ambiental e recursos de conservação, são alguns exemplos (SOCIAL CREDIT WATCH, 2019).
}

Sistema Nacional de Publicidade e Informação sobre Crédito Empresarial - NECIPS ${ }^{33}$ em sítio eletrônico pelas mídias sociais oficiais estatais e exibidas em locais públicos, como estações de trens.

Já a terceira etapa consiste na Estrutura de Recompensas e Punições $^{34}$. Trata-se de uma série de acordos legais em que os órgãos governamentais se comprometem, reciprocamente, a cumprir os propósitos por trás de suas Listas Negras e Vermelhas. Uma vez incluída a pessoa natural ou jurídica em uma das "Listas" por uma autoridade local, o registro se vincula ao seu histórico de crédito. Em seguida, a informação é compartilhada pela $N C I S P$ e pelo NECIPS, de forma a circular por outros níveis governamentais. Tem-se, portanto, um "efeito cascata", em que as penalidades e recompensas são aplicáveis pelas mais diversas autoridades ${ }^{35}$.

\footnotetext{
${ }^{33}$ Tradução livre para National Enterprise Credit Information Publicity System. (SOCIAL CREDIT WATCH, 2019).

${ }^{34}$ Tradução livre para Unified Rewards and Punishments (SOCIAL CREDIT WATCH, 2019).

${ }^{35}$ Dentre as agências governamentais, em nível nacional, que mais concebem recompensas e punições, destacam-se: Administração Geral Alfandegária,
} 


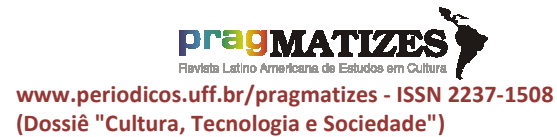

Além disso, constata-se um intenso fomento à cultura do crédito social por parte do governo central às municipalidades e provincialidades, para que elas criem seus próprios mecanismos de punições e recompensas, preferencialmente, de forma a definir o acesso a serviços públicos $^{36}$. Em maio de 2019, mais de 300 aplicações e projetos participaram da "Copa do Crédito", promovido pela emissora estatal Xinhua. Nessa toada, instaura-se uma retroalimentação do uso dos dados. O governo central os colhe $e$ os fornece a diferentes aplicações e autoridades locais por meio de sua "Base Central"- NCISP e os aplicativos os requalificam conforme a interação das pessoas.

privilegiando ou sancionando importações e exportações de companhias; Ministério de Ecologia e Meio Ambiente, aumentando ou diminuindo taxas de consumo de energia elétrica; Administração de Aviação Civil, impedindo o acesso ou oferecendo cortesias em viagens; e Administração do Ciberespaço, censurando aqueles que violem a "moralidade social, ética nos negócios, honestidade e integridade" no âmbito virtual (SOCIAL CREDIT WATCH, 2019).

${ }^{36} \mathrm{Em}$ junho deste ano o governo elaborou uma cartilha às autoridades locais para fomentar o bom comportamento de crédito, de forma a oferecer tratamento preferencial em serviços públicos, tais como acordos, educação, viagens, moradia, emprego, saúde e questões burocráticas (GOVERNO POPULAR CENTRAL, 2019).
Atualmente, existem centenas de aplicações desenvolvidas pelas autoridades locais em parceria com empresas de crédito privado, operacionalizando e fomentando 0 $S_{C S}{ }^{37}$. Dentre essas, há aplicações que avaliam comportamentos pessoais e as que, efetivamente, ranqueiam os indivíduos através de notas.

Dentre as aplicações avaliadoras de comportamentos, o aplicativo Chengxin Chunyun ${ }^{38}$ concebe um sistema de crédito social que avalia comportamentos considerados perturbadores e ilegais dentro de meios de transporte, como aviões, trens e embarcações (ABACUS, 2019). Lutar, quebrar equipamentos, fumar, embarcar sem multa, abrir saídas de emergência, são algumas condutas que podem resultar na proibição de viagens futuras. Tais circunstâncias são relatadas a diversas agências governamentais nacionais ${ }^{39}$. O aplicativo aceita relatórios positivos e negativos sobre a qualidade do serviço de transporte e o

\footnotetext{
${ }^{37}$ Inclusive ganhadoras de prêmios em eventos promovidos pelo governo chinês (CREDIT CHINA, 2019).

${ }^{38}$ Desenvolvido pelas empresas Tianxia Credit e Pengyuan Credit (SCHAEFER, 2019).

${ }^{39}$ Tais como o próprio NDRC, Ministério dos Transportes, Secretaria de Segurança Pública, Administração da Aviação Civil, Companhia Ferroviária da China (SHAEFER, 2019).
} 


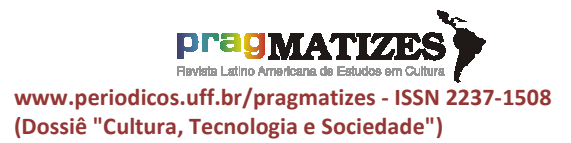

comportamento dos passageiros. Os utentes podem fazer uploads de evidências fotográficas $e$, depois que os incidentes forem investigados e verificados, os relatórios serão registrados no arquivo de crédito social da pessoaalvo.

Já a plataforma Laolai Checker $^{40}$, por sua vez, fornece dados à "Lista Negra dos Infratores"41, mantida pela Supremo Tribunal Popular, contendo informações de indivíduos e companhias que falharam em cumprir decisões judiciais.Os usuários podem pesquisar pelo nome dos inadimplentes, visualizar detalhes do histórico jurídico e ver o status atual de cumprimento. Além disso, disponibiliza-se um mapa, em tempo real, com a localização dos devedores de "Listas Negras" mais próximos às pessoas. Ou seja, trata-se de um monitoramento em tempo real e, inclusive, da localização dos cidadãos, o que além de violar em larga escala a privacidade, possibilita confrontos sociais indesejáveis.

Além disso, um vazamento divulgado pelo Consórcio Internacional

\footnotetext{
${ }^{40}$ Desenvolvida pela empresa Xiamen Tuoke Network Company (SHAEFER, 2019).

${ }^{41}$ Tradução livre para Defaulter Blacklist.
}

de Jornalistas Investigativos ${ }^{42}$ revelou que a popular plataforma Zapya ${ }^{43}$ intensifica a opressão aos uigures ${ }^{44}$ detidos na região de Xinjiang ${ }^{45}$. Por meio da instalação compulsória do aplicativo, autoridades locais monitoram e controlam todas as atividades civis do grupo minoritário de etnia muçulmana. Dentre os

\footnotetext{
${ }^{42}$ Tradução livre para International Consortium of Investigative Journalists. O escândalo denominou-se China Cables ou Xinjiang Papers. Adoção do nome se dá de forma similar ao Panama Papers, quando há uma imensa quantidade de documentos secretos vazados, no caso, mais de 400 páginas, já traduzidas do chinês para o inglês, conforme matéria jornalística investigativa disponibilizada pelo jornal The New York Times (RAMZY; BUCKLEY, 2019).

${ }^{43}$ Muçulmanos em todo o mundo estão migrando para um aplicativo móvel de compartilhamento de arquivos chamado Zapya, desenvolvido por uma startup de Pequim que incentiva os usuários a baixar o Alcorão e compartilhar ensinamentos religiosos com entes queridos (ALECCI, 2019).

${ }^{44} \mathrm{O}$ regime de Xi Jinping, em sua campanha de repressão contra a minoria muçulmana uigur, não só acelerou a prisão forçada de moradores de Xinjiang - a ONU calcula que pelo menos um milhão de uigures estão presos em campos - , como também tentou vigiar todos os seus movimentos no estrangeiro. $E$ para isso estendeu os tentáculos de seu macrossistema de vigilância a embaixadas e consulados, dos quais obtém informação e através dos quais persegue essa minoria (GARRIDO; GRASSO, 2019).

${ }^{45}$ However, the UN believes Xinjiang to be the site of potential systemic human-rights abuses against Muslim minorities. Since 2017, China is widely reported to have detained more than a million - some estimates put the figure at three million - Uighur Muslims in detention facilities that Beijing has described as vocational training centres (WITHNALL, 2020).
} 


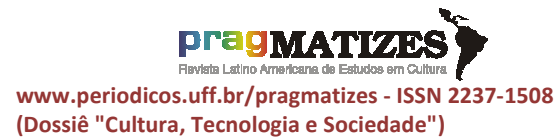

mecanismos de coerção impostos pelo governo central, no caso específico dos uigures, há um sistema de controle comportamental traduzido em pontos pautados em condutas após processos de "transformação ideológica, estudos, treinamento e compromisso com a disciplina"46, que pode resultar em punições mais severas ou em recompensas como a permissão para fazer contato com a família. Importante ressaltar que no SCS existem proibições específicas quanto à inclusão de dados sobre crenças religiosas, por exemplo. No entanto, ao que parece, comprovado pela análise do caso dos uigures, essa informação pode ser extraída dos dados comportamentais gerais, o que, sem dúvida, é um grave problema.

Ainda não existe uma plataforma nacional que avalie os indivíduos em notas quanto à reputação. No entanto, existem algumas aplicações concebidas por autoridades locais que desenvolvem tal mecanismo e que, efetivamente, adotam um sistema de pontuação de indivíduos, que controla o acesso a

\footnotetext{
${ }^{46}$ Consoante as informações analisadas por Sophie Richardson, diretora da Human Rights Watch para a China (BBC, 2019).
}

benefícios sociais. As notas atribuídas variam em escalas numéricas. Em Suzhou, as pontuações variam de 0 a 200; em Hangzou, de 0 a 1000. E mesmo nas cidades que utilizam as mesmas escalas, os modelos algorítmicos utilizados podem ser bem distintos $^{47}$.

A cidade de Nanjing desenvolveu a plataforma My Nanjing, que disponibiliza diversas informações civis $^{48}$ e possibilita que tudo possa ser atendido na mesma aplicação ${ }^{49}$. Nele, há um sistema de avaliação dos indivíduos, em que são concedidos "pontos verdes" com base em condutas como andar a pé e utilizar transporte público. Há, portanto, somente um sistema de recompensas, sem (ainda) quaisquer punições.

Por sua vez, na cidade de Xiamen há o Xiamen Egret Points, que

\footnotetext{
${ }^{47}$ Com base na comparação dos diferentes modelos implementados por cidades chinesas (SCHAEFER, 2019).

${ }^{48}$ São alguns exemplos: a malha do transporte urbano, dados ambientais, hospitais, prestadores de serviços públicos, pontos turísticos, agências de assuntos civis, tribunais, escolas, instituições financeiras locais e organizações de caridade (SHAEFER, 2019).

${ }^{49}$ Tais como: ver multas e alertas de trânsito, pagar contas e impostos, marcar consultas médicas, fazer investimentos bancários, procurar ajuda jurídica, requerer informações cartorárias, candidatar-se em trabalho voluntário (SHAEFER, 2019).
} 


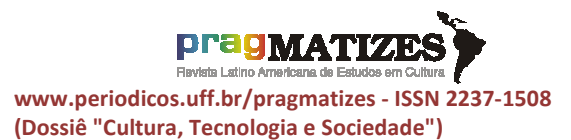

forja, da mesma forma, tão somente um sistema de recompensas, em um formato de ranking dos indivíduos, utilizando os dados da NCISP. No entanto, as recompensas se limitam a empréstimos gratuitos em bibliotecas, aluguel de bicicleta sem depósito e descontos em estacionamentos. Assim, verifica-se uma baixa adesão da população.

Nesse sentido, não levou tempo para que o SCS se adaptasse às medidas de contenção quanto à disseminação do novo COVID-19. Cidades como Hangzou publicaram em sua lista negra municipal o nome de nove pessoas que tentaram fraudar seu histórico de viagens. Passada a humilhação desses indivíduos, eles terão que assinar um termo em que se comprometem a se tornar honestos. Em Rongcheng, doações de dinheiro ou materiais de proteção ao vírus aumentam a pontuação ali existente. Em Zhucheng, as equipes médicas se destacam na frente dos demais cidadãos, mas a adoção de comportamentos não-confiáveis pode gerar o banimento de abrir negócios, o impedimento de empregos no governo e até de deixarem o país ${ }^{50}$.

Além disso, de acordo com informações publicadas pelo The New York Times ${ }^{51}$, foi implantada, coercitivamente, uma série de mecanismos de monitoramento eletrônico nos celulares chineses, até então sem precedentes. O Alipay Health Code $^{52}$, software médico de monitoramento eletrônico, determina a obrigatoriedade da permanência em quarentena, por meio da classificação das pessoas como sendo "verdes",

${ }^{50}$ Conforme informações relatadas pela Wired (WIRED, 2020).

${ }^{51}$ Such surveillance creep would have historical precedent, said Maya Wang, a China researcher for Human Rights Watch. China has a record of using major events, including the 2008 Beijing Olympics and the 2010 World Expo in Shanghai, to introduce new monitoring tools that out last their original purpose, Ms. Wang said (MOZUR, Paul; ZHONG, Raymond; KROLIK, Aaron, 2020).

${ }^{52}$ The epidemic prevention map of Digital China is advancing at the speed of the Internet. The typical representative of this is Alipay Health Code. After the Alipay Health Code was launched in Hangzhou on February 11, it has landed in more than 100 cities within a week. On February 15, the E-Government Office of the General Office of the State Council instructed Alipay and Alibaba Cloud to accelerate the development of a national integrated government service platform for epidemic prevention and control health codes. Subsequently, Sichuan, Zhejiang, and Hainan achieved province-wide coverage. A digital anti-epidemic "Skynet" is being fully rolled out at the speed of China, and Alipay health code has become the standard for digital epidemic prevention in various places (XINHUANET, 2020). 


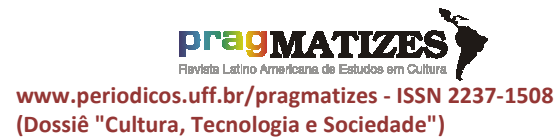

"amarelas" e "vermelhas", em alusão aos sinais de trânsito $^{53}$. Tal classificação, que corresponde a um tipo de estigmatização, ocorre sem qualquer explicação oficial por parte do governo central, possuindo ainda falhas ${ }^{54}$.

No âmbito dessa pesquisa, observou-se que as aplicações que efetivamente avaliam os comportamentos dos indivíduos são mais perigosas do que as que atribuem notas aos cidadãos. Isso porque, são já compulsórias e lhes causam represálias por quaisquer motivos de inadimplência, adoção de comportamentos reprováveis ou por questões puramente preconceituosas e xenófobas. Há, nesse viés, violação à dignidade humana, em seus quatro substratos $^{55}$ : (i) ao estabelecer um

\footnotetext{
${ }^{53}$ People in China sign up through Ant's popular wallet app, Alipay, and are assigned a color code - green, yellow or red - that indicates their health status. The system is already in use in 200 cities and is being rolled out nationwide, Ant says (Idem, 2020).

${ }^{54}$ Conforme as informações reportadas pelo The New York Times, Vanessa Wong, residente na província de Hubei, foi obrigada a ficar em casa por semanas, por ser classificada com um sinal vermelho, mesmo não tendo qualquer sintoma do coronavírus (Idem, 2020).

${ }^{55}$ Acerca dos quatro substratos da dignidade da pessoa humana, explicita Maria Celina Bodin de Moraes: O substrato material da dignidade assim entendida pode ser desdobrado em quatro postulados: i) o sujeito
}

tratamento legalmente desigual entre sujeitos; (ii) ao aviltar a integridade física e moral das pessoas ao estigmatizá-las e rotulá-las; (iii) ao violar a incolumidade física quanto à liberdade de se locomover livremente; e (iv) ao criar uma sociedade que, efetivamente, isola indivíduos à convivência sadia e empática.

Além disso, os dados que compõe a NCISP, categorizados em 400 variáveis, são angariados de forma manifestamente imprecisa $e$ temerária. De acordo com um relatório governamental ${ }^{56}$, tornam-se objeto de registro, a ser compartilhado com o "povo supremo" (toda a população), dados como: retaliações por relatar informações, estar sendo processado por informações, penalidades comportamentais e administrativas; e, a ser compartilhado entre os ministérios, informações acerca de:

moral (ético) reconhece a existência dos outros como sujeitos iguais a ele; ii) merecedores do mesmo respeito à integridade psicofísica de que é titular; iii) é dotado de vontade livre, de autodeterminação; iv) é parte do grupo social, em relação ao qual tem a garantia de não vir a ser marginalizado. São corolários desta elaboração os princípios jurídicos da igualdade, da integridade física e moral - psicofísica -, da liberdade e da solidariedade (2003, p. 83).

${ }^{56}$ Conforme disposição do Gabinete de Comissão Nacional de Desenvolvimento e Reforma (HBC CREDIT, 2019). 


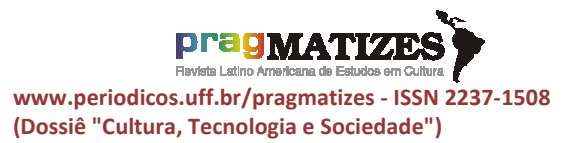

estudantes com bolsa de estudos, obtenção de grau acadêmico no exterior, relatos morais sobre professores, dados médicos quanto a doenças infectocontagiosas, aspectos ruins encontrados em aplicativos de dispositivos móveis, registros nominais na internet, etc. Tal lógica, em que controlado se torna controlador, funciona em analogia às contemporâneas inovações tecnológicas de facilidade de obtenção dos dados, tornando o sistema mais eficiente e previsível, fenômeno já observado por Stefano Rodotà ${ }^{57}$

Ressalte-se que,o relatório supramencionado é datado de $2016^{58}$. Embora ainda não haja confirmação acerca da utilização de câmeras de vigilância com reconhecimento facial

\footnotetext{
${ }^{57}$ Porém o reconhecimento de um direito de acesso aos bancos de dados públicos (e privados) demonstra que esse não é o único modelo possível: o controlado pode se tornar, por sua vez, controlador, tornando desta forma mais transparentes os comportamentos de quem colhe as informações. Assim como a inovação tecnológica progressivamente pôs em funcionamento instrumentos de comunicação de mão dupla, também a inovação institucional pode tornar efetivos sistemas de controle em mão dupla, que partam da coletividade em direção aos bancos de dados e não somente do alto em direção ao baixo (2008, p. 47).

${ }^{58}$ Conforme disposição do Gabinete de Comissão Nacional de Desenvolvimento e Reforma (HBC CREDIT, 2019).
}

pelo sistema ${ }^{59}$, sabe-se que este tipo de mecanismo foi amplamente utilizado para conter o avanço do COVID-19. Para se ter uma ideia, no ano passado eram cerca de 200 milhões de câmeras do tipo espalhadas pelas ruas; até o final deste ano, o número chegará a mais de600 milhões de dispositivos ${ }^{60}$. A falta de transparência e de acessibilidade revela-se alarmante, considerando que os dados "roubados" dos cidadãos enquadrar-se-ão em "Listas Negras" ou "Vermelhas"para, consequentemente, fundamentar a

\footnotetext{
${ }^{59}$ Another fear is that data collection at the heart of the social credit system will eventually include facial recognition from traffic systems, identifying people and their locations in an instant. But despite concerns about high-tech artificial intelligence and facial recognition being applied to social credit, much of the system today boils down to sharing information like driver's licenses, court records or government awards certifications from one government office to another (BORAK, 2019).

${ }^{60} \mathrm{O}$ país é conhecido por empregar uma ampla rede de tecnologias de monitoramento, que inclui a coleta dados sobre viagens de seus cidadãos, a vigilância de redes sociais e da internet e o uso de softwares de reconhecimento facial em locais públicos: estimativas apontam que a China poderá ter mais de 600 milhões de câmeras com esse mecanismo até o fim de 2020. O governo afirma que todo esse aparato faz parte de uma estratégia de segurança para identificar criminosos, mas críticos do sistema acusamno de violar a privacidade e de ser usado para perseguir opositores políticos e minorias (CARBINATTO, 2020)
} 
decisão de quem terá acesso à cidadania.

Cria-se um cenário onde estão presentes: i) opacidade,resultado da obscuridade quanto a funcionalidades do sistema; ii) escala, elevada ao país mais populoso do mundo ${ }^{61}$; e iii) dano, verificada nas violações a direitos humanos. Tais elementos ensejam a formação de uma "arma de destruição matemática"62, expressão cunhada pela matemática Cathy O’Neil para descrever aplicações com embasamento matemático que potencializam a economia de dados baseados nas escolhas feitas por tão falíveis seres humanos (2016, p. 2).

A deflagração de tal sistema tecnopolítico se dá mediante formas disruptivas de controle estatal sobre a população, em que a hiperconectividade da vida humana se traduz em hipervigilância governamental. O resultado é 0 constante estado de insegurança e de violações à autodeterminação informativa. Em suma, tem-se a ressignificação da cidadania pautada no produto de algoritmos externos

\footnotetext{
${ }^{61}$ Conforme dados estatísticos do Banco Mundial de 2018 (ibid, 2020).

62 Tradução livre para Weapons of Math Destruction.
}

potencialmente

enviesados

e completamente alheios aos indivíduos. Trata-se do biopoder, fenômeno observado por Michel Foucault ainda no séc. $X X^{63}$, potencializado pelo desenvolvimento tecnológico atual e agravado por ser operacionalizado não apenas pelo governo, mas por empresas privadas a partir das aplicações acima mencionadas.

Destarte, analisando-se a opacidade quanto à funcionalidade dos algoritmos externos existentes nos sistemas de pontuações de crédito nos Estados Unidos ${ }^{64}$, Frank Pasquale assinala que tais pontuações escaparam de seu contexto financeiro e se estabilizaram como árbitros de

\footnotetext{
${ }^{63}$ Aquém, portanto, do grande poder absoluto, dramático, sombrio que era o poder da soberania, e que consistia em poder fazer morrer, eis que aparece agora, com essa tecnologia do biopoder, com essa tecnologia do poder sobre a 'população' enquanto tal, sobre o homem enquanto ser vivo, um poder contínuo, científico, que é o poder de 'fazer viver'. A soberania fazia morrer e deixava viver. $\mathrm{E}$ eis que agora aparece um poder que eu chamaria de regulamentação e que consiste, ao contrário, em fazer viver e em deixar morrer. (FOUCAULT, 2010, p. 207).

${ }^{64}$ Corrobora-se, a título de exemplo do contexto estadunidense de concessão de crédito, a instituição financeira Goldman Sachs vem sendo investigada pelo Departamento de Serviços Financeiros de Nova York, sob suspeita da adotarem algoritmos com vieses sexistas, verificados após denúncias de que quanto aos limites de crédito concedidos ao cartão Apple Card,mulheres estariam recebendo limites menores do que homens (MATSUURA, 2019).
} 


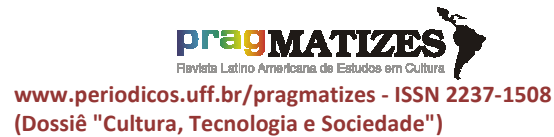

confiabilidade em geral em áreas distintas (2015, p. 23). Por derradeiro, a pontuação de crédito se torna um fator decisivo em determinar o sucesso ou o fracasso de um indivíduo, tradução de estar na "Lista Vermelha" ou na "Lista Negra" chinesa por meio de avaliações de uma sociedade de vigilância.

Nesse contexto, é possível observar a mudança paradigmática de uma "sociedade disciplinar" para a "sociedade de desempenho" ou "sociedade do cansaço", constatada pelo filósofo Byung-Chil Han (2015, p. 25). A constante busca pela maximização da produção e do poder, como ocorre na China, resulta neste eficiente mecanismo de controle estatal, próprio do séc. XXI. O monitoramento e a vigilância intrínsecos ao desenvolvimento humano concebem a violenta autoexploração individual. "O explorador é ao mesmo tempo o explorado. Agressor e vítima não podem mais ser distinguidos. Essa autorreferenciabilidade gera uma liberdade paradoxal que, em virtude das estruturas coercitivas que lhe são inerentes, se transforma em violência" (ibid, p. 30).
A comparação com o primeiro episódio da terceira temporada da série Black Mirror ${ }^{65}$, Nosedive, parece inevitável. Na trama, Lacie vive em um mundo aparentemente idílico, onde o nível de gentileza e simpatia é mensurado por meio de uma instantânea e habitual avaliação recíproca entre as pessoas através de seus smartphones (algo como a ambição governamental chinesa). No entanto, na forma visceral como é abordado 0 desenvolvimento tecnológico, é possível perceber suas implicações extremamente negativas, isto é, os efeitos nefastos de um sistema que rotula de forma arbitrária e superficial indivíduos dotados de identidades e peculiaridades próprias, gerando desconfiança, preconceitos e marginalizações (tal como pode se elevar o SCS ${ }^{66}$.

\footnotetext{
${ }^{65}$ Black Mirror é uma da série da Netflix, originária da televisão britânica, antológica de ficção científica criada por Charlie Brooker e centrada em temas obscuros e satíricos que examinam a sociedade moderna, particularmente a respeito das consequências imprevistas das novas tecnologias.

${ }^{66}$ Nesse sentido, Arthur Coelho Bezerra sintetiza a correlação da ficção idealizada na série, com aspectos da realidade:não estando limitadas aos interesses diretos de um governo totalitário, as práticas individuais de vigilância de pessoas sobre outras pessoas em sociedades consideradas democráticas se alastram através de outros agenciamentos sociotécnicos, que encontram no voyeurismo
} 


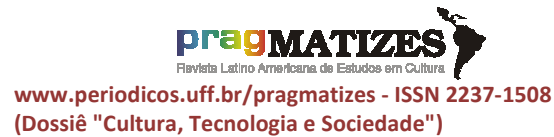

Sentiu-se falta de inserir um dado real, diretamente obtido através de um cidadão do país, que contribuísse com uma visão "de dentro", da pessoa que sofre cotidianamente o impacto do sistema em sua vida e privacidade. Ou seja, pareceu importante tentar compreender um pouco melhor 0 sistema a partir do ponto de vista de um cidadão. Essa busca, limitada às possibilidades disponíveis, conduziu ao estabelecimento de contato com um grupo de chineses que lecionam o idioma mandarim no Rio de Janeiro ${ }^{67}$ e uma chinesa concordou em conceder uma entrevista sobre o SCS. Residente há alguns anos no Brasil,

midiático um estímulo para que uns vigiem os outros. Em Nosedive, todas as conversas e demais interações pessoais, tradicionalmente inseridas em uma economia invisível de trocas simbólicas, ganham materialidade em um sistema de avaliações instantâneas por celular, que são computadas para gerar notas para cada indivíduo. Como mencionado, as notas afetam não apenas as relações sociais, mas também as possibilidades de acesso a trabalho e a serviços básicos, levando às últimas consequências a perspectiva deleuziana das sociedades de controle, segundo a qual "os indivíduos tornaram-se 'dividuais', divisíveis, e as massas tornaram-se amostras, dados, mercados ou 'bancos' (2018, p. 30).

${ }^{67}$ Será resguardado o nome do estabelecimento de línguas, direito constitucionalmente assegurado pelo artigo 5o, XIV da Constituição da República (BRASIL, 1988).
Xiao Wang ${ }^{68}$ acredita que, na prática, muitos chineses foram indiferentes à instituição do SCS, visto que a maioria da população já segue estritamente as duras regras socialmente impostas pelo Estado. Portanto, segundo ela, a população não se sente afetada direta e negativamente pelo sistema. Ressalta que, no geral, os chineses não veem com "maus olhos", mas sim como uma ferramenta a mais, usada para "incentivar" as pessoas a cumprirem com seus deveres e obrigações.

No entanto, como Xiao Wang não mora mais no país, não soube dar muitos detalhes sobre o estado atual do sistema, se circunscrevendo a repassar as informações conforme relatos de amigos próximos que ainda moram na China. Em suas palavras: "acho que o povo já sofre tanto com controle do Estado, que para eles só foi mais uma dentre as formas de controle. Na prática, para quem já segue as regras, acaba sendo indiferente" (informação verbal) ${ }^{69}$.

\footnotetext{
${ }^{68}$ Nome fictício com o intuito de preservar a identidade real da entrevistada.

${ }^{69}$ Entrevista fornecida por Xiao Wang aos autores no Rio de Janeiro, em outubro de 2019.
} 


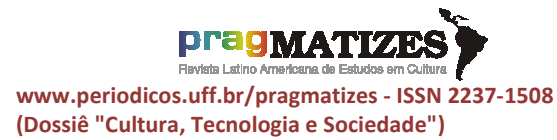

Com efeito, subsiste uma série de equívocos e mal-entendidos quanto à compreensão mundial do sistema de crédito social chinês, muito em função de existirem inúmeras barreiras socioculturais. Por exemplo, a conjugação das palavras "crédito social" pode ter interpretações distintas na comparação linguística sinoportuguesa. No mundo ocidental, o termo foi concebido pelo engenheiro Clifford Douglas ${ }^{70}$, como um mecanismo de maior intervenção social nas relações econômicas. Já no oriente, sobretudo na China, o termo se assemelha à "confiança pública"71 ou a um "termo de trabalho"72.

\footnotetext{
${ }^{70}$ Não estamos acusando o poder financeiro de hostilidade maligna à sociedade, embora seus efeitos sejam tais que tornem a acusação plausível. O efeito é inerente à separação do Crédito Real do Crédito Financeiro - Crédito Social, ou seja, do Crédito Financeiro controlado por empresas privadas. E o principal objetivo do presente Esquema é restaurar à comunidade o uso pleno do Crédito Financeiro como um instrumento necessário para o uso pleno do seu Crédito Real. Esperamos que os meios sejam mais claros à medida que prosseguirmos (DOUGLAS, 1921, p. 166).

${ }^{71}$ To an English speaker, the two words together might signal a reference to interpersonal relationships. In Chinese, the term is more closely associated with a phrase like "public trust."(MATSAKIS, apud DAUM, 2019).

${ }^{72}$ Some of the mischaracterized accounts in foreign media are understandable given the loose use of the phrase "social credit" (社会信用, shehuixinyong) in China. One law professor I spoke to in Beijing encouraged me
}

\section{Sistema de Crédito Social no} Brasil?

Naturalmente, Brasil e China são países distintos, com regimes políticos diferentes e com especificidades socioculturais também distintas. Nesse contexto, poder-se-ia concluir que um sistema de crédito social seria inviável no Brasil. Talvez, um sistema da magnitude do chinês esteja longe da nossa realidade, mas certamente, há diversos sistemas de vigilância e, sim, avaliadores e ranqueadores de nossos comportamentos.

A rigor, existem diferenças importantes entre os dois ordenamentos jurídicos, sobretudo, quanto ao direito à privacidade e à segurança dos dados pessoais. Porém, a comparação se demonstra pertinente em um contexto de globalização. No Brasil, por exemplo, já é uma realidade e com a sua licitude reconhecida pelo $S T J^{73}$, a utilização do

to think of it as a "working term," an umbrella category encompassing several moving parts of a broader policy agenda that includes both national initiatives as well as city-level pilot projects that do not generalize to a country wide scale (AHMED, 2019).

${ }^{73}$ Consoante entendimento firmado na Súmula no 550 do STJ: "A utilização de escore de crédito, método estatístico de avaliação de 
escore de crédito, consistente em método matemático de análise de concessão de crédito para as relações de consumo. Esse sistema não necessita da expressa autorização dos indivíduos e a licitude da aplicação da ferramenta se fundamenta no artigo 5으, IV, da Lei do Cadastro Positivo (Lei $n^{\circ}$ 12.414/11), que estabelece condição sine qua non de que os consumidores têm direito de "conhecer os principais elementos e critérios considerados para a análise de risco, resguardado o segredo empresarial" ${ }^{\prime 4}$.

As informações que compõem as pontuações de crédito devem ser intrínsecas à análise do crédito, sendo vedado o uso de informações de dados pessoais sensíveis ${ }^{75}$. Tal

risco que não constitui banco de dados, dispensa o consentimento do consumidor, que terá o direito de solicitar esclarecimentos sobre as informações pessoais valoradas e as fontes dos dados considerados no respectivo cálculo" (STJ, 2015).

${ }^{74}$ Art. 5ำ, Lei no 12.414/11: São direitos do cadastrado: IV - conhecer os principais elementos e critérios considerados para a análise de risco, resguardado o segredo empresarial (BRASIL, 2011).

${ }^{75}$ Consoante Art. 7--A, Lei no 12.414/11: Nos elementos e critérios considerados para composição da nota ou pontuação de crédito de pessoa cadastrada em banco de dados de que trata esta Lei, não podem ser utilizadas informações: I - que não estiverem vinculadas à análise de risco de crédito e aquelas relacionadas à origem social e étnica, à saúde, à informação genética, ao sexo e às exigência vai ao encontro da Lei Geral de Proteção de Dados (Lei no 13.709/18), diploma que regula a coleta, uso, tratamento e compartilhamento de dados, que, provavelmente, entrará em vigor em maio de 2021, consoante a postergação determinada pela Medida Provisória no 959/202076. A LGPD, em consonância com a legislação europeia de proteção de dados, determina que 0 tratamento e utilização de dados pessoais sensíveis ${ }^{77}$ seja excepcional e em hipóteses específicas, tendo como

convicções políticas, religiosas e filosóficas (BRASIL, 2011).

${ }^{76}$ De acordo com o art. 4 a MP no 959/2020, à exceção dos dispositivos que regulam a Autoridade Nacional de Proteção de Dados ANPD, os demais artigos da LGPD entrarão em vigor em maio de 2021. Cumpre ressaltar que a possibilidade de adiamento da lei de proteção de dados estava sendo negociada no Congresso Nacional e, até o presente momento, foi aprovada a prorrogação escalonada, isto é, os dispositivos referentes à ANDP entrariam em vigor em janeiro de 2021, enquanto os demais artigos, em agosto de 2021, conforme disposto no Projeto de Lei no 1179/2020, responsável pela prorrogação de prazos contratuais privados devido à pandemia do COVID-19.

${ }^{77}$ Também disciplinados na LGPD;Art. 5으, Lei n 13.709/18: Para os fins desta Lei, considerase: II - dado pessoal sensível: dado pessoal sobre origem racial ou étnica, convicção religiosa, opinião política, filiação a sindicato ou a organização de caráter religioso, filosófico ou político, dado referente à saúde ou à vida sexual, dado genético ou biométrico, quando vinculado a uma pessoa natural (BRASIL, 2018). 
regra, o consentimento prévio do titular $^{78}$. Ressalta-se que a própria LGPD admite o tratamento de dados pessoais à tutela de crédito em seu art. $7^{\circ}, \mathrm{X}$.

Dentre as iniciativas governamentais envolvendo coleta e tratamento de dados, ou seja, iniciativas de tecnopolítica, merecem destaque as inovações legislativas que têm por objeto diversas modalidades de controle social a partir da criação de bancos de dados.

Os Decretos oㅜ 10.046/19 e no 10.047/19 criaram o Cadastro Base do Cidadão $^{79}$, o Comitê Central de Governança de $\operatorname{Dados}^{80}$, além do Cadastro Nacional de Informações Sociais - $\mathrm{CNIS}^{81}$. Nas palavras do

\footnotetext{
${ }^{78}$ Art. 11 , Lei no 13.709/18: O tratamento de dados pessoais sensíveis somente poderá ocorrer nas seguintes hipóteses:I - quando o titular ou seu responsável legal consentir, de forma específica e destacada, para finalidades específicas; II - sem fornecimento de consentimento do titular, nas hipóteses em que for indispensável para: (...) (BRASIL, 2018).

${ }^{79}$ Art. 16, Decreto № 10.046/19: Fica instituído o Cadastro Base do Cidadão com a finalidade de: (...) (BRASIL, 2019).

${ }^{80}$ Art. 21, Decreto № 10.046/19: Fica instituído o Comitê Central de Governança de Dados, a quem compete deliberar sobre: (...) (BRASIL, 2019).

${ }^{81}$ Art. 1을 Decreto no 10.047/19: Este Decreto dispõe sobre a governança do Cadastro Nacional de Informações Sociais - Cnis e institui o programa Observatório de
}

secretário de Governo Digital do Ministério da Economia, Luis Felipe Monteiro, à época da promulgação, "o objetivo é que o Cadastro Base do Cidadão se consolide como a única referência de informações dos cidadãos para o governo. Será composto pelos dados do CPF e também pela integração de dados específicos de outras bases dos órgãos públicos" (MINISTÉRIO DA ECONOMIA, 2019).

Na prática, podem ser objeto de compartilhamento entre entidades da Administração Pública Federal, dados cadastrais $^{82}$, além de atributos biográficos $^{83}, \quad$ genéticos $^{84} \quad \mathrm{e}$

Previdência e Informações do Cnis(BRASIL, 2019).

${ }^{82}$ Art. 2o, Decreto no $10.046 / 19$ : Para fins deste Decreto, considera-se: III - dados cadastrais informações identificadoras perante os cadastros de órgãos públicos, tais como: a) os atributos biográficos; $b$ ) o número de inscrição no Cadastro de Pessoas Físicas - CPF; c) o número de inscrição no Cadastro Nacional de Pessoas Jurídicas - CNPJ; d) o Número de Identificação Social - NIS; e) o número de inscrição no Programa de Integração Social PIS; f) o número de inscrição no Programa de Formação do Patrimônio do Servidor Público Pasep; g) o número do Título de Eleitor; h) a razão social, o nome fantasia e a data de constituição da pessoa jurídica, o tipo societário, a composição societária atual e histórica e a Classificação Nacional de Atividades Econômicas - CNAE; e i) outros dados públicos relativos à pessoa jurídica ou à empresa individual (BRASIL, 2019).

${ }^{83}$ Art. 2을 Decreto no 10.046/19: Para fins deste Decreto, considera-se: I - atributos biográficos - dados de pessoa natural relativos 


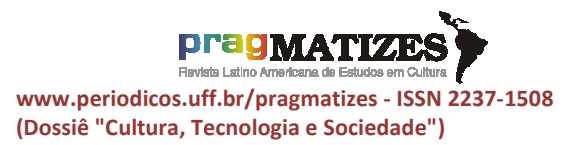

biométricos. Estes, nada mais são do que "características biológicas e comportamentais mensuráveis da pessoa natural que podem ser coletadas para reconhecimento automatizado, tais como a palma da mão, as digitais dos dedos, a retina ou a íris dos olhos, o formato da face, a voz e a maneira de andar" (BRASIL, 2019). Com o fito de facilitar o compartilhamento e o cruzamento ${ }^{85}$ de informações inerentes a 210 milhões de pessoas $^{86}$, será depositada ao Cadastro de Base do Cidadão, contendo, minimamente, dados cadastrais e biográficos ${ }^{87}$. Por sua vez,

aos fatos da sua vida, tais como nome civil ou social, data de nascimento, filiação, naturalidade, nacionalidade, sexo, estado civil, grupo familiar, endereço e vínculos empregatícios (BRASIL, 2019).

${ }^{84}$ Art. ${ }^{2}$, Decreto № 10.046/19: Para fins deste Decreto, considera-se: IV - atributos genéticos - características hereditárias da pessoa natural, obtidas pela análise de ácidos nucleicos ou por outras análises científicas (BRASIL, 2019).

\footnotetext{
${ }^{85}$ Art. 16, Decreto no $10.046 / 19$. Fica instituído o Cadastro Base do Cidadão com a finalidade de: $\mathrm{V}$ - facilitar o compartilhamento de dados cadastrais do cidadão entre os órgãos da administração pública; e VI - realizar o cruzamento de informações das bases de dados cadastrais oficiais a partir do número de inscrição do cidadão no CPF (BRASIL, 2019).

${ }^{86}$ Conforme dados estatísticos do Instituto Brasileiro de Geografia e Estatística- IBGE (IBGE,2020).

${ }^{87}$ Art. 18, Decreto no 10.046/19. A base integradora será, inicialmente, disponibilizada com os dados biográficos que constam da
}

a fiscalização e administração dessa valiosa massa de dados ficará a cargo exclusivo $^{88}$ de membros do Poder Executivo,por meio do Comitê Central de Governança de Dados.

Paralelamente, no Decreto no 10.047/19, há o compartilhamento de dados entre as entidades federais, voltado à formação de uma base de informação laborais e previdenciárias, o denominado Cadastro Nacional de Informações Sociais - CNIS. Por sua vez, a administração dessa base de dados ficará a cargo do Instituto Nacional de Seguro Social - INSS ${ }^{89}$.

base temática do CPF. $\S 1^{\circ}$ Os atributos biográficos e cadastrais que inicialmente comporão a base integradora serão, no mínimo, os seguintes: (...) (BRASIL, 2019).

${ }^{88}$ Art. 22, Decreto no 10.046/19: O Comitê Central de Governança de Dados é composto por representantes dos seguintes órgãos $e$ entidade:I - dois do Ministério da Economia, dentre os quais um da Secretaria Especial de Desburocratização, Gestão e Governo Digital, que o presidirá, e um da Secretaria Especial da Receita Federal do Brasil;II - um da Casa Civil da Presidência da República;III - um da Secretaria de Transparência e Prevenção da Corrupção da Controladoria-Geral da União;IV - um da Secretaria Especial de Modernização do Estado da Secretaria-Geral da Presidência da República;V - um da Advocacia-Geral da União; e VI - um do Instituto Nacional do Seguro Social(BRASIL, 2019).

${ }^{89}$ Art. 3o, Decreto no 10.047/19: Compete ao Instituto Nacional do Seguro Social - INSS: I administrar e operacionalizar o Cnis, com base nas orientações e nos atos normativos editados pela Secretaria Especial de Previdência e Trabalho do Ministério da Economia; II - administrar e gerir permissões e níveis de acesso ao Cnis e suas informações; 


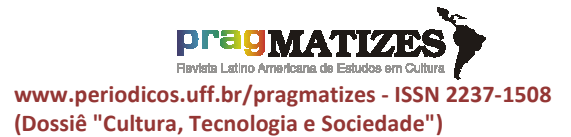

Compor-se-ão ao CNIS cinquenta e uma bases dos mais variados sistemas e repositórios, contendo informações sensíveis como, por exemplo, dados relativos à saúde, cadastros de informação de gestantes $^{90}$, câncer de mama ${ }^{91}$ e de colo de útero ${ }^{92}$; e dados relativos à educação, envolvendo programas de financiamento estudantil ${ }^{93}$ e frequência escolar ${ }^{94}$. Além disso, no que toca ao acesso e à obtenção dos dados que comporão o CNIS, consoante artigo $3^{\circ}$, $\S^{0}$ - do referido decreto, "fica dispensada a celebração de convênio, acordo de cooperação técnica ou instrumentos congêneres para a

III - administrar e gerir as demandas de desenvolvimento do Cnis; IV - incorporar ao Cnis as informações necessárias à concessão, à manutenção, à revisão e às verificações periódicas de benefícios administrados pelo INSS; e V - encaminhar à Secretaria Especial de Previdência e Trabalho do Ministério da Economia propostas de ações ou de normativos relacionados às competências de que trata o art. 2을 (BRASIL, 2019).

${ }^{90} 24$. Sistema de Acompanhamento da Gestante -SisPreNatal (BRASIL, 2019).

${ }^{91} 33$. Sistema de Informação do câncer de mama -Sismama (BRASIL, 2019).

92 32. Sistema de Informação do câncer do colo do útero -Siscolo (BRASIL, 2019).

${ }^{93} 14$. Programa Universidade para Todos ProUni; 17. Financiamento Estudantil - Fies (BRASIL, 2019).

${ }^{94} 16$. Monitoramento da frequência escolar do Programa Bolsa Família - Presença (BRASIL, 2019). efetivação do compartilhamento de dados com o INSS" (BRASIL, 2019).

Nesse diapasão, constata-se a criação de um massivo aparato de vigilância estatal, dotado de extrema vagueza quanto à motivação, modus operandi e destinação final dos dados passiveis de coleta. Reafirma-se a fatídica consequência do capitalismo de vigilância, em que informações tão ricas, em ambos os sentidos existencial e patrimonial da palavra, são relativizadas e apequenadas frente à redação normativa empregada, bem como à opção legislativa utilizada. Esse contexto e as potencialidades dessas novas proposições legislativas se tornam ainda mais preocupantes no contexto social brasileiro, visto que as pessoas se preocupam pouco com os seus dados pessoais ou, ainda que se preocupem, entendem como benéfico o oferecimento de seus dados em troca de supostas vantagens ${ }^{95}$.

\footnotetext{
95 "As pessoas ainda se preocupam pouco com os seus dados no Brasil. Somos uma nação que informa o CPF na farmácia só para ver se tem desconto e que cadastra a digital dos dedos para entrar na academia de ginástica. Você sabe o que a farmácia faz com a ligação entre o seu CPF e a lista de remédios que você compra? Você sabe com quem mais a sua academia compartilha um dado tão essencialmente identificador como a digital do seu dedo? A digital é um dado tão
} 


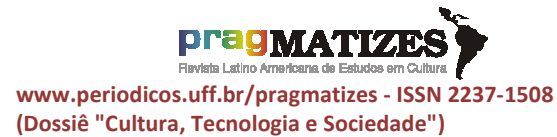

Interessante notar que, enquanto 0 Cadastro de Base do Cidadão tem por finalidade "aumentar a confiabilidade dos cadastros de cidadãos existentes na administração pública, por meio de mecanismos de manutenção da integridade das bases de dados para torná-las qualificadas e consistentes" (BRASIL, 2019), o Social Credit System afirma que "a virtude é um requisito interno, e o mecanismo de recompensa e punição se baseia na confiabilidade e não confiabilidade, com o objetivo de melhorar a integridade e o nível de crédito de toda a sociedade" (CHINA, 2014). Não obstante a menção ao mecanismo de recompensa e punição, é possível inferir, pela dicção dos comandos sinobrasileiros, o elevado grau de similaridade entre os sistemas tecnopolíticos, conforme já apontado por alguns especialistas ${ }^{96}$.

poderoso que ele é requerido quando você viaja para entrar em países com esquemas mais rigorosos de segurança nas fronteiras e aeroportos. Mais uma razão para você se sentir um turista quando for na sua academia (SOUZA, Carlos Affonso, 2019).

${ }^{96} \mathrm{O}$ decreto de Bolsonaro vai na contramão do que a gente vê em países como Reino Unido, Austrália, Canadá e Finlândia, de ter um nível de uso de dados com certa interoperablidade entre eles, feito dentro de um ordenamento de transparência, com instrumentos que dão controle ao cidadão de como o dado dele é usado. A gente não vê nada disso nesse
Nesse cenário, a LGPD se caracteriza como um importante instrumento para a tutela e orientação do tratamento dos dados pessoais, frente à resistente cultura de relativização destes. Sua importância é demonstrada, inclusive, diante do atual cenário de pandemia mundial, constatado pelo aumento exponencial de medidas arbitrárias e temerárias a adequada tutela dos dados pessoais ${ }^{97}$. Imperioso destacar, nesse viés, que a própria edição da Lei nำ 13.979/20, que dispõe sobre as medidas de enfrentamento do COVID-19, possui pontos problemáticos, como a obrigatoriedade de compartilhamento de dados sensíveis entre os órgãos da Administração Pública Federal ${ }^{98}$ e a

decreto. (...) é como se o Brasil tivesse aberto mão dos bons exemplos desses países e tivesse optado por uma mistura do Aadhaar, da Índia, com o credit score da China (DE LUCA, apud DONEDA, 2019).

${ }^{97}$ Aqui no Brasil, esses projetos também já começaram a ser feitos. Um grupo de operadoras - Algar Telecom, Claro, Oi, Tim e Vivo - vão disponibilizar um grande banco de dados para o Ministério da Ciência, Tecnologia, Inovações e Comunicações (MCTIC), a partir das informações de suas torres de transmissão, que podem identificar a movimentação das pessoas (ROMANI, 2020).

${ }^{98}$ Art. 6으, Lei no 13.979/20: É obrigatório o compartilhamento entre órgãos e entidades da administração pública federal, estadual, distrital e municipal de dados essenciais à identificação de pessoas infectadas ou com suspeita de infecção pelo coronavírus, com a 


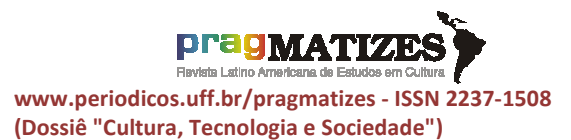

(Dossiê "Cultura, Tecnologia e Sociedade") suspensão de prazos quanto aos pedidos de acesso à informação dos referidos órgãos federais ${ }^{99}$.

Mais recentemente, em outro desdobramento da mencionada lei de enfrentamento ao novo coronavírus (Lei n 13.979/20), a Medida Provisória no 954, de 17 de abril de 2020, determina que empresas de telefonia repassem dados de clientes ao IBGE, tais como, nomes, números de telefone e endereços de seus consumidores, pessoas naturais ou jurídicas ${ }^{100}$,enquanto perdurar o atual estágio de prevenção ao COVID-19, sob a justificativa de tratar-se de fins

finalidade exclusiva de evitar a sua propagação (BRASIL, 2020).

${ }^{99}$ Art.6-ㅡ, Lei no 13.979/20: Serão atendidos prioritariamente os pedidos de acesso à informação, de que trata a Lei no 12.527 , de 2011, relacionados com medidas de enfrentamento da emergência de saúde pública de que trata esta Lei. $\S 1^{\circ}$ Ficarão suspensos os prazos de resposta a pedidos de acesso à informação nos órgãos ou nas entidades da administração pública cujos servidores estejam sujeitos a regime de quarentena, teletrabalho ou equivalentes e que, necessariamente, dependam de: I acesso presencial de agentes públicos encarregados da resposta; ou II - agente público ou setor prioritariamente envolvido com as medidas de enfrentamento da situação de emergência de que trata esta Lei (BRASIL, 2020).

${ }^{100}$ Art. 2º, Medida Provisória no 954/20: As empresas de telecomunicação prestadoras do STFC e do SMP deverão disponibilizar à Fundação IBGE, em meio eletrônico, a relação dos nomes, dos números de telefone e dos endereços de seus consumidores, pessoas físicas ou jurídicas (BRASIL, 2020). meramente estatísticos. Apesar da normativa vedar o compartilhamento dos dados ${ }^{101}$ e de tratar-se o IBGE de um órgão de Estado, detentor de toda a credibilidade por ser responsável pela coleta, tratamento e análise das estatísticas oficiais do país, há uma clara violação aos princípios da finalidade e necessidade do uso dos dados. Não à toa, este foi também o entendimento adotado pelo STF ao derrubar liminarmente a medida, asseverando que a suspensão visa "prevenir danos irreparáveis à intimidade e ao sigilo da vida privada de mais de uma centena de milhão de usuários dos serviços de telefonia fixa e móvel"102.

${ }^{101}$ Art. 3o-Medida Provisória no 954/20: Os dados compartilhados: I - terão caráter sigiloso; II - serão usados exclusivamente para a finalidade prevista no $\S 1^{\circ}$ do art. $2^{\circ}$; e III não serão utilizados como objeto de certidão ou meio de prova em processo administrativo, fiscal ou judicial, nos termos do disposto na Lei ํㅡ 5.534, de 14 de novembro de 1968. § 1ํE vedado à Fundação IBGE disponibilizar os dados a que se refere 0 caput do art. $2^{\circ}$ a quaisquer empresas públicas ou privadas ou a órgãos ou entidades da administração pública direta ou indireta de quaisquer dos entes federativos (BRASIL, 2020).

${ }^{102}$ Consoante decisão liminar da Ministra Rosa Weber, de 24/04/2020: "a fim de prevenir danos irreparáveis à intimidade e ao sigilo da vida privada de mais de uma centena de milhão de usuários dos serviços de telefonia fixa e móvel, com o caráter precário próprio aos juízos perfunctórios e sem prejuízo de exame mais aprofundado quando do julgamento do mérito, defiro a medida cautelar 
Sendo assim, com a provável postergação da LGPD, o cenário delineado quanto ao tratamento de dados pessoais se torna ainda mais preocupante em tempos de relativização das liberdades civis e direitos fundamentais que visam 0 controle e contenção do novo vírus. A propósito, o contexto de sucessivas medidas temerárias à segurança dos dados pessoais não se restringe à seara civil, mas também à criminal. Segue em vigor a Lei do Pacote Anticrime (Lei o 13.964/19), que dentre as controversas medidas de recrudescimento penal, objeto de debates $^{103}$, destaca-se 0 dispositivo que prevê o alargamento do Banco Nacional de Perfis Genéticos -

requerida, ad referendum do Plenário desta Suprema Corte, para suspender a eficácia da Medida Provisória n. 954/2020, determinando,em consequência, que o Instituto Brasileiro de Geografia e Estatística IBGE se abstenha de requerer a disponibilização dos dados objeto da referida medida provisória e, caso já o tenha feito, que suste tal pedido,com imediata comunicação à(s) operadora(s) de telefonia" (STF, 2020).

${ }^{103}$ A ADIN no 6.345 proposta pela ANADEP Associação Nacional das Defensoras e dos Defensores Públicos questiona no STF dispositivos do pacote anticrime (Lei 13.964/19) que tratam dos aumentos de pena, tornam mais rigoroso o regime de cumprimento da pena privativa de liberdade e restringe direitos já concedidos (MIGALHAS, 2020).
$\mathrm{BNPG}^{104}$, instituído pela Lei de Identificação Criminal (Lei $\mathrm{n}$ ำ 12.037/09), bem como a criação do Banco Nacional Multibiométrico e de Impressões Digitais - BNMID. Este, "tem como objetivo armazenar dados de registros biométricos, de impressões digitais e, quando possível, de íris, face e voz, para subsidiar investigações criminais federais, estaduais ou distrital”"105.

Malgrado questionar-se a própria eficácia em se adotar mais mecanismos de punição como instrumento de ressocialização de pessoas condenadas criminalmente, tem-se uma imensa relativização aos direitos constitucionalmente assegurados de não apenas não produzir provas contra si mesmo ${ }^{106}$, como de não permitir a violação de

\footnotetext{
${ }^{104}$ Dentre os mecanismos de alargamento do Banco Nacional de Perfis Genéticos - BNPG destacam-se a compulsoriedade à submissão de coleta de dados genéticos, em que a recusa incide em falta grave aos condenados,

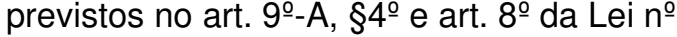
13.964/19 (BRASIL, 2019).

${ }^{105}$ Art. 7ㅇ-C, § 2ํ, Lei oํ 13.964/19 (BRASIL, 2019).

${ }^{106}$ Art. 5o, LXIII, CFRB 1988 - o preso será informado de seus direitos, entre os quais o de permanecer calado, sendo-lhe assegurada a assistência da família e de advogado (BRASIL, 1988).
} 


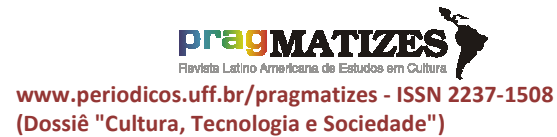

sua integridade psicofísica ${ }^{107}$. Não há, nesse viés, quaisquer menções à regulamentação e ao tratamento de dados biológicos na LGPD, tampouco à Lei de Identificação Criminal, fazendo com que a medida de caráter compulsório, seja extremamente arbitrária à dignidade da pessoa humana ${ }^{108}$.

Ao analisar a

constitucionalidade da criação do

Banco Nacional Multibiométrico e de Impressões Digitais - BNMID, o Instituto Brasileiro de Ciências Criminais - IBCCRIM ${ }^{109}$, entidade não-

${ }^{107}$ Art. 5ㅇ, XLIX, CFRB 1988 - é assegurado aos presos o respeito à integridade física $\mathrm{e}$ moral (BRASIL, 1988).

${ }^{108}$ No direito brasileiro, após mais de duas décadas de ditadura sob o regime militar, a Constituição democrática de 1988 explicitou, no artigo 1, III, a dignidade da pessoa humana com um dos "fundamentos da República". A dignidade humana, assim, não é criação da ordem constitucional, embora seja por ela protegida. A Constituição consagrou o princípio e, considerando a sua eminência, proclamou-o entre os princípios fundamentais, atribuindo-lhe o valor supremo de alicerce da ordem jurídica democrática (BODIN DE MORAES, 2003, p. 83).

${ }^{109}$ O IBCCRIM, ao concluir pela inconstitucionalidade duvidosa da criação do Banco Nacional Multibiométrico e de Impressões Digitais - BNMID, destacando: "No mais, ainda que a modernização das formas de identificação seja, de certa forma, natural, há que se ter algum cuidado com a criação de um projeto como esse, especialmente no que diz respeito à violação de privacidade. Um banco de voz ou face, em tese, pode individualizar uma pessoa mesmo sem o auxílio de qualquer método adicional ou governamental voltada à promoção de direitos humanos na seara criminal, esclarece que, no tocante à colheita de padrões de voz, o STF já asseverou que a coerção do acusado a ceder padrões amostrais de sua voz para fins periciais acarreta em nulidade processual por violação do privilégio contra sua não-incriminação ${ }^{110}$.

Noutro giro, quanto à realidade chinesa, infere-se que uma série de aspectos sociais, políticos, econômicos e culturais propiciam um ambiente favorável à implementação do sistema. Trata-se de um país onde há 70 anos vigora o único Partido Comunista da China (PCC $)^{111}$, historicamente marcado por sucessivos governos centralizados de

sem coleta de material biológico, por meio do uso de aplicativos específicos. No limite, um banco de voz e face permitiria a base de um sistema global de espionagem de indivíduos em público. Esse perigo de violação de privacidade e vazamento de dados sensíveis deve ser avaliado em termos de custobenefício, e ser objeto de maior discussão entre especialistas em segurança digital antes de serem previstos em lei" (IBCCRIM, 2019).

${ }^{110}$ STF. Habeas Corpus no 83.096 / RJ. Segunda Turma. Ministra Relatora Ellen Gracie. Data de julgamento: 12/12/2003.

${ }^{111}$ Há 70 (setenta) anos, em 1ㅇ de outubro de 1949, a China deu início à Revolução Comunista, promovida por Mao Tsé-tung, estabelecendo o Partido Comunista da China (PCC), poder único que controla todo o país (BBC BRASIL, 2019). 


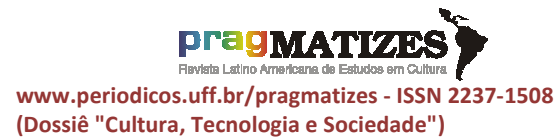

intenso controle e autoritarismo ${ }^{112}$. Peculiaridades que atreladas ao atual estado da era dos dados, potencializam-se, mediante a sofisticação de mecanismos de coerção e vigilância. $\mathrm{O}$ resultado é a extrema relativização dos direitos humanos e fundamentais.

A conjectura sociopolítica chinesa e sua consequente cultura de crédito social é uma realidade distante da de muitos países democráticos ${ }^{113}$. A vigilância massiva e o controle sobre dados são uma ameaça quase universal às nações, seja mediante o domínio de empresas privadas, seja por ingerências governamentais. A propósito, tais mecanismos de controle

\footnotetext{
${ }^{112} \mathrm{O}$ estado de constante vigilância e controle assemelha-se ao modelo arquitetônico do Panóptico, segundo ao qual consegue: induzir no detento um estado consciente e permanente de visibilidade que assegura o funcionamento automático do poder. Fazer com que a vigilância seja permanente em seus efeitos, mesmo se é descontínua em sua ação; que a perfeição do poder tenda a tornar inútil a atualidade de seu exercício; que esse aparelho arquitetural seja uma máquina de criar e sustentar uma relação de poder independente daquele que o exerce; enfim, que os detentos se encontrem presos numa situação de poder de que eles mesmos são os portadores (FOUCAULT, 1999, p. 217-218)

${ }^{113}$ Consoante relatório publicado pela The Economist, em 2015, 79 países enquadravamse ao ranking de Democracias Plena ou Imperfeita. O Brasil enquadra-se na $51^{\underline{a}}$ posição, como Democracia Imperfeita e a China em 136ª , como Regime Autoritário (THE ECONOMIST, 2015).
}

já atingiram um ponto crítico de violações aos direitos humanos ${ }^{114}$. Nesse sentido, ao constatar que o país mais populoso do mundo está em vias de substituir a autodeterminação de sua população por um sofisticado sistema tecnopolítico, vê-se a distorção do significado de cidadania com o fito de atender a incessantes buscas de maximização de lucros e de crescimento econômico.

Tal realidade não é diferente no Brasil. No plano governamental, a insegurança quanto à proteção dos dados também é identificada em tendências arbitrárias praticadas pelo Poder Público. Claros exemplos de tais inclinações são constatáveis nos recentes Decretos no 10.046/19 e no 10.047/19, bem como na Lei do Pacote Anticrime, todos originários da atual gestão do Governo Federal. A rigor, o Brasil demonstra adotar

\footnotetext{
${ }^{114}$ De acordo com o relatório publicado em novembro deste ano, pela Anistia Internacional, o Google e o Facebook, e seus demais domínio, estabeleceram o maior domínio de controle fora da China, onde detêm a onipresença da vigilância e do controle de dados.Constatou que as condutas abusivas praticadas por essas companhias atingiram um ponto crítico, deflagrado por um modelo de negócios incompatível com o direito à privacidade, representa uma ameaça a direitos como liberdade de opinião e expressão, liberdade de pensamento e direito à igualdade e não discriminação (ANISTIA INTERNACIONAL, 2019).
} 


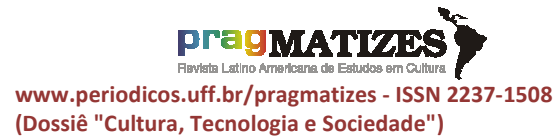

(Dossiê "Cultura, Tecnologia e Sociedade") algumas medidas semelhantes àquelas adotadas na China no que tange ao uso disruptivo de dados, demonstrado por ações recentes tomadas pelo Poder Executivo Federal. Assim, "se não tivermos cuidado, o resultado disso poderia ser um estado de polícia orwelliano, que constantemente monitora e controla não somente todos os nossos atos, mas até mesmo o que acontece dentro de nossos corpos e cérebros" 115

Em vistas deste cenário, se torna necessária a construção de um componente ético apto a ampliar para os novos meios tecnológicos o valor da dignidade da pessoa humana, inserida cada vez mais em ciberespaços. Isto porque, 0 desenvolvimento algorítmico e suas inteligências artificiais somente se

115 "Se não tivermos cuidado, o resultado disso poderia ser um estado de polícia orwelliano, que constantemente monitora e controla não somente todos os nossos atos, mas até mesmo o que acontece dentro de nossos corpos e cérebros. Imagine-se apenas os usos que Stálin poderia achar para sensores biométricos onipresentes e que usos Putin ainda pode achar para eles. No entanto, enquanto os defensores da individualidade humana temem uma repetição de pesadelos do século XX e se preparam para resistir aos familiares inimigos orwellianos, a individualidade humana enfrenta agora uma ameaça ainda maior que vem de direção oposta. No século XXI há mais probabilidade de que o indivíduo se desintegre suavemente por dentro do que brutalmente esmagado por fora (HARARI, 2016, p. 374). mostram merecedores de tutela se devidamente funcionalizados pelos elementos principiológicos inerentes à tábua axiológica constitucional, tais como o respeito à vida privada, à individualidade e à autodeterminação. Os indivíduos detêm 0 direito de participar da era virtual, de forma segura e protetiva, porquanto, as palavras "pessoas" e "dados" são redundantes, cuja tutela de uma resulta no intrínseco respeito à outra $^{116}$.

\section{Considerações finais}

O presente trabalho buscou realizar uma análise do atual sistema de controle de dados pessoais do governo chinês, o SCS, à luz da metodologia civil constitucional.

Em vista à atual conjectura da era dos dados, verificada pela dicotômica relação entre 0 enriquecimento dos meios tecnológicos e o empobrecimento de valores humanos, constata-se o franco

\footnotetext{
${ }^{116}$ Diante da multiplicação de situações trazidas pelas novas tecnologias, muda-se radicalmente a técnica legislativa, valendo-se o legislador de inúmeras cláusulas gerais - as quais permitem ao intérprete amolda às previsões normativas às peculiaridades do caso concreto -, e os princípios, dotados de força normativa, tornam-se fundamentais para determinação dos ordenamentos aplicáveis aos casos concretos, cada vez mais inusitados (TEPEDINO, 2009, p. 17).
} 
desenvolvimento de sistemas privados e públicos invasivos à privacidade e à autodeterminação informativa. Em países de baixa ou recente democracia, infere-se que a cultura de vigilância já existentes se tornam otimizados à adoção de medidas ainda mais latentes e invasivas.

Nesse viés, os mecanismos de vigilância e controle de dados, formalmente instaurados na China (por meio do SCS) e identificados em recentes medidas do Poder Executivo Federal (por meio de leis, decretos e medidas provisórias) no Brasil, revelam-se inconcebíveis sob o prisma existencial da pessoa humana, cuja não observância de sua dignidade não faz jus às vagas justificativas de construção de integridade ou confiabilidade nos respectivos âmbitos nacionais. Não se nega, entretanto, que a realidade chinesa é extremamente agravada pela falta de garantias e de liberdades, marcada pelo regime totalitário, no qual vigora 0 sistema único de filiação política há quase um século. O sistema de crédito social é, de fato, a transfiguração coercitiva à era digital.

Este mecanismo, denominado Social Credit System, ainda se encontra em estágio inicial, gerando uma série de imprecisões quanto às suas finalidades. Ainda assim, é possível identificar três pontos nevrálgicos de sua funcionalidade sistêmica. Primeiramente, há um massivo compartilhamento de dados, compilados a uma base central. A seguir, tem-se as subjetivas avaliações sociocomportamentais de indivíduos, de modo a classificá-los em dicotômicas listas, boas e ruins. Por fim, consoante as rotulações estabelecidas nas listas, aplicam-se os instrumentos de punições e recompensas, regulando a efetiva participação e acesso de indivíduos à cidadania. O sistema se retroalimenta por constantes coletas e requalificações dos dados, angariados sem quaisquer consentimentos, de forma aleatória e difusa. Subsiste-se uma temerária tentativa chinesa em definir conceitos obscuros de boa cidadania. Como resultado, tem-se a uma sociedade de desempenho voltada à autoexploração dos indivíduos.

Partindo-se para análise do contexto nacional, reconhece-se a existência do escore de crédito, em que as pontuações individuais se 


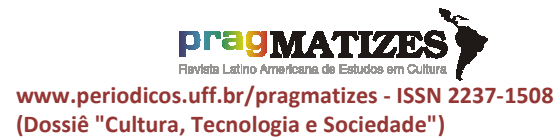

(Dossiê "Cultura, Tecnologia e Sociedade") limitam às relações consumeristas, encontrando freios em importantes movimentos regulatórios como a Lei do Cadastro Positivo e a Lei Geral de Proteção de Dados. Ainda assim, constata-se uma forte cultura de desvalorização dos dados pessoais, sobretudo, sob seu viés existencial. Tal fato é corroborado pelas diversas medidas promovidas pela atual gestão do Governo Federal, em perigosas relativizações do uso e tratamento de dados pessoais coletados por entidades públicas, permitindo-se coletas, inclusive, de dados pessoais sensíveis, genéticos e biológicos.

Destaca-se a urgência da construção de um componente ético norteador do desenvolvimento e utilização desses meios tecnológicos, de forma a assegurar o valor da dignidade da pessoa humana e os direitos fundamentais nos ciberespaços. O desenvolvimento tecnológico não será interrompido e qualquer tentativa nesse sentido seria inócua e em total descompasso com um cenário social já existente e prevalente. Por outro lado, se torna imprescindível a adoção de um elemento ético no desenvolvimento tecnológico e algorítmico. O desafio posto à civilização humana mostra, dentre outras questões, a conscientização de que "pessoa" e "dado" são sinônimos e a tutela protetiva de um impõe o mesmo dever sobre o outro.

Consoante tais preconizações básicas, chega-se ao fim desta análise, sem a pretensão de esgotar o debate. Considera-se um avanço em si mesmo a oportunidade de agregar alguma reflexão a tema tão urgente e de importância sem precedentes. Ressalta-se a necessidade de buscar uma atenta percepção das formulações jurídicas e políticas no que tange ao tema do uso dos dados, bem como das demais contribuições acadêmicas provenientes das mais variadas áreas, com o objetivo de alcançar mais esclarecimento e informação. Este será dentre outros temas, como as mudanças climáticas e as pandemias como o COVID-19, um dos maiores desafios a serem enfrentados pela comunidade mundial. Adota-se um viés otimista de se ter, ainda, o acesso à discussão, posto que, em futuro próximo, arrisca-se a ser afirmado que "com exceção dos poucos centímetros que cada um possuía dentro do crânio, ninguém 
RITO, Fernanda; GUEIROS, Pedro Teixeira. O Social Credit System na Era dos Dados. PragMATIZES - Revista Latino-Americana de Estudos em Cultura, Niterói/RJ, Ano 10, n. 19, p. 170-213, set. 2020.

tinha nada de seu" (ORWELL, 2009, p. 35).

\section{Referências bibliográficas}

ABACUS. China's super-app We Chat now let's flyers pay offline on flights. Disponível em: scmp.com/tech/bigtech/article/3029501/chinas-super-appwechat-now-lets-flyers-pay-offlineflights. Acesso: nov. 2019.

ADALMA, Zigor. Surgirá uma inteligência maior do que a humana? Disponível em: https://brasil.elpais.com/brasil/2019/07/ 29/tecnologia/1564354846_969018.ht ml. Acesso: nov. 2019.

AHMED, Shazeda. The Messy Truth About Social Credit. Disponível em: https://logicmag.io/china/the-messytruth-about-social-credit/. Acesso: out. 2019.

ALECCI, Scilla. How China Targets Uighurs 'One By One' For Using $A$ Mobile App. Disponível em: https://www.icij.org/investigations/china -cables/how-china-targets-uighurs-oneby-one-for-using-a-mobile-app/.

Acesso: nov. 2019.

ALLEN-EBRAHIMIAN, Bethany. Exposed: China's Operating Manuals For Mass Internment And Arrest By Algorithm. Disponível em: https://www.icij.org/investigations/china -cables/exposed-chinas-operatingmanuals-for-mass-internment-andarrest-by-algorithm/. Acesso: nov. 2019.

ANISTIA INTERNACIONAL. Surveillance giants: how the business model of Google and Facebook threatens human rights. Disponível em: https://www.amnesty.org/en/document s/pol30/1404/2019/en/. Acesso: nov. 2019.

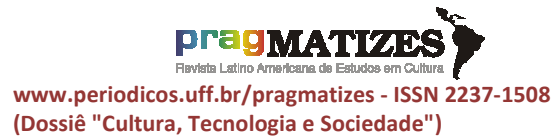

ASIAPEDIA. Cyber-security law of the People's Republic of China. Disponível em:

https://www.dezshira.com/library/legal/ cyber-security-law-china-8013.html.

Acesso: nov. 2019.

BANCO MUNDIAL. Population, total China. Disponível em: https://data.worldbank.org/indicator/SP .POP.TOTL? locations=CN. Acesso: abr. 2020.

BBC BRASIL. 70 anos da Revolução na China: Como o Partido Comunista controla o país. Disponível em: bbc.com/portuguese/internacional49890359. Acesso: out. 2019.

BBC BRASIL.Entenda o escândalo de uso político de dados que derrubou valor do Facebook e o colocou na mira de autoridades. Disponível em: https://www.bbc.com/portuguese/intern acional-43461751. Acesso: out. 2019.

BBC BRASIL. Os documentos secretos que revelam lavagem cerebral de presos de minoria étnica na China. Disponível em: https://www.bbc.com/portuguese/intern acional-50543654. Acesso: abr. 2020.

BEZERRA, Arthur Coelho. Os reflexos do Grande Irmão no admirável espelho novo de Black Mirror. In: BRANCO, Sérgio; TEFFÉ, Chiara Spadaccini de (orgs.). Privacidade em Perspectiva. Rio de Janeiro: Lumens Juris: 2018.

BODIN DE MORAES, Maria Celina. Danos à pessoa humana: uma leitura civil-constitucional dos danos morais. Rio de Janeiro: Renovar, 2003.

BODIN DE MORAES, Maria Celina. $\mathrm{Na}$ medida da pessoa humana: estudos de direito civil-constitucional. Rio de Janeiro: Renovar, 2010.

BORAK, Masha. China isusing social credit apps to 'gamify government'. 
Disponível

em:

https://www.abacusnews.com/tech/chi na-using-social-credit-apps-gamifygovernment/article/3033202. Acesso: nov. 2019.

BRASIL. Constituição da República Federativa do Brasil de 1988. Disponível em: http://www.planalto.gov.br/ccivil_03/co nstituicao/constituicao.htm. Ácesso: out. 2019.

BRASIL. Decreto no 10.046 de 09 de outubro de 2019. Dispõe sobre a governança no compartilhamento de dados no âmbito da administração pública federal e institui o Cadastro Base do Cidadão e o Comitê Central de Governança de Dados. Disponível em:

http://www.planalto.gov.br/ccivil_03/_at o2019-

2022/2019/decreto/D10046.htm.

Acesso: nov. 2019.

BRASIL. Decreto no 10.047 de 09 de outubro de 2019. Dispõe sobre a governança do Cadastro Nacional de Informações Sociais e institui o programa Observatório de Previdência e Informações, no âmbito do Cadastro Nacional de Informações Sociais. Disponível em: http://www.planalto.gov.br/ccivil_03/_at 02019-

2022/2019/decreto/D10047.htm.

Acesso: nov. 2019.

BRASIL. Lei no 12.414 de 09 de junho de 2011. Disciplina a formação e consulta a bancos de dados com informações de adimplemento, de pessoas naturais ou de pessoas jurídicas, para formação de histórico de crédito. Disponível em: http://www.planalto.gov.br/ccivil_03/_at o2011-2014/2011/lei/l12414.htm.

Acesso: out. 2019.
BRASIL. Lei no 13.709 de 14 de agosto de 2018. Lei Geral de Proteção de Dados Pessoais (LGPD). Disponível em: http://www.planalto.gov.br/ccivil_03/_at o2015-2018/2018/lei/L13709.htm.

Acesso: out. 2019.

BRASIL. Lei $n^{\circ} 13.797$ de 06 de fevereiro de 2020. Dispõe sobre as medidas para enfrentamento da emergência de saúde pública de importância internacional decorrente do coronavírus responsável pelo surto de 2019. Disponível em: http://www.planalto.gov.br/ccivil_03/_at o2019-2022/2020/lei/L13979.htm.

Acesso: abr. 2020.

BRASIL. Lei no 13.964 de 24 de dezembro de 2019. Aperfeiçoa a legislação penal e processual penal. Disponível em: http://www.planalto.gov.br/ccivil_03/_at o2019-2022/2019/lei/L13964.htm.

Acesso: fev. 2020.

BRASIL. Lei no 13.965 de 23 de abril de 2014. Estabelece princípios, garantias, direitos e deveres para 0 uso da Internet no Brasil. Disponível em:

http://www.planalto.gov.br/ccivil_03/_at o2011-2014/2014/lei/l12965.htm.

Acesso: out. 2019.

BRASIL. Lei no 8.078 de 11 de setembro de 1990. Dispõe sobre a proteção do consumidor e dá outras providências. Disponível em: http://www.planalto.gov.br/ccivil_03/leis /18078.htm. Acesso: abr. 2020.

BRASIL. Medida Provisória no 954 de 17 de abril de 2020. Dispõe sobre o compartilhamento de dados por empresas de telecomunicações prestadoras de Serviço Telefônico Fixo Comutado e de Serviço Móvel Pessoal com a Fundação Instituto Brasileiro de Geografia e Estatística, para fins de 


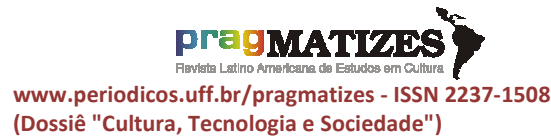

suporte à produção estatística oficial durante a situação de emergência de saúde pública de importância internacional decorrente do coronavírus (covid-19), de que trata a Lei $\mathrm{n}^{\circ}$ 13.979, de 6 de fevereiro de 2020. Disponível em: http://www.planalto.gov.br/CCIVIL_03/ Ato2019-

2022/2020/Mpv/mpv954.htm. Acesso: abr. 2020.

BRASIL. Medida Provisória no 959 de 29 de abril de 2020. Estabelece a operacionalização do pagamento do Benefício Emergencial de Preservação do Emprego e da Renda e do benefício emergencial mensal de que trata a Medida Provisória $\mathrm{n}^{\circ}$ 936, de 1은 de abril de 2020 , e prorroga a vacatio legis da Lei no 13.709, de 14 de agosto de 2018, que estabelece a Lei Geral de Proteção de Dados Pessoais LGPD. Disponível em: http://www.in.gov.br/web/dou/-/medidaprovisoria-n-959-de-29-de-abril-de2020-254499639. Acesso: abr. 2020.

BRASIL. Projeto de Lei Anticrime. Disponível em: https://www.justica.gov.br/news/collecti ve-nitf-content-1549284631.06/projetode-lei-anticrime.pdf. Acesso: nov. 2019.

BROOKS, David. The Philosophy of Data. Disponível em: nytimes.com/2013/02/05/opinion/brook s-the-philosophy-of-data.html. Acesso: nov. 2019.

CAMPBELL, Charlie; CHENGDU.How China Is Using "Social Credit Scores" to Reward and Punish Its Citizens. Disponível em:

https://time.com/collection/davos2019/5502592/china-social-creditscore/. Acesso em: outubro, 2019.

CARBINATTO, Bruno. China está usando vigilância em massa para combater coronavirus. Disponível em: https://super.abril.com.br/tecnologia/chi na-esta-usando-tecnologias-devigilancia-em-massa-para-combatercoronavirus/. Acesso: abr. 2020.

CHINA. Aviso do Conselho de Estado sobre Impressão e Distribuição do Esboço da Construção do Sistema de Crédito Social (2014-2020). Disponível em:

http://www.gov.cn/zhengce/content/20 14-06/27/content_8913.htm. Acesso: set. 2019.

COMITÊ TÉCNICO NACIONAL DE PADRONIZAÇÃO DE SEGURANÇA DA INFORMAÇÃO DA CHINA. Informação de Segurança e Tecnologia (Tradução livre). Disponível em:

https://www.tc260.org.cn/upload/201801-24/1516799764389090333.pdf.

Acesso: nov. 2019.

COMITÊ TÉCNICO NACIONAL DE PADRONIZAÇÃO DE SEGURANÇA DA INFORMAÇÃO DA CHINA (TC260). Especificação de Segurança de Informações Pessoais. Disponível em:

https://www.tc260.org.cn/upload/201801-24/1516799764389090333.pdf.

Acesso: out.2019.

CREDIT CHINA.2019 "Xinhua Credit Cup" National Credit Case Collection and Credit Application Scenario Excellent Micro Video Call for Event Winning Works Announcement. Disponível em: https://credit.ankang.gov.cn/web/cont 2c817d96d2944fb9bc1f85f51183ca6f.h tml. Acesso em: novembro, 2019.

CREDIT CHINA. Credit e-government website navigation. Disponível em: https://www.creditchina.gov.cn/wangzh andaohang_newOne/?navPage $=15$. Acesso: out. 2019. 


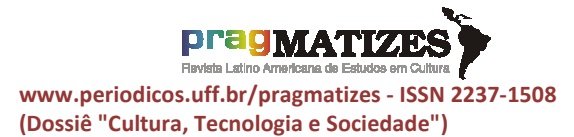

CREDIT CHINA. Nanjing won another award at the 2019 National Credit Summit Forum. Disponível em: http://www.njcredit.gov.cn/xydt/201909/ t20190927_5959670.html. Acesso: out. 2019.

DE LUCA, Cristina. Decreto de Bolsonaro aproxima uso de nossos dados a países como China. Disponível em: https://porta23.blogosfera.uol.com.br/2 019/10/13/governo-tem-nossos-dadosmas-nao-deve-trata-los-como-sefosse-o-dono-deles/. Acesso: out. 2019.

DE TEFFÉ, Chiara Spadaccini. A saúde na sociedade da vigilância: como proteger os dados sensíveis? Disponível em: https://m.migalhas.com.br/coluna/migal has-de-vulnerabilidade/324485/asaude-na-sociedade-da-vigilanciacomo-proteger-os-dadossensiveis?fbclid=IwAR2ybqQmoskHgU 8Es62BAiujo9bpOSS_FZLergSljSrSHd yHaZKYXkppW24. Acesso: abr. 2020.

DEBORD, Guy. A sociedade do espetáculo: comentários sobre a sociedade do espetáculo. Rio de Janeiro: Contraponto, 1997.

DOUGLAS, Clifford Hugh. CreditPower and Democracy. Londres: Cecil Palmer, 1921.

ENCCLA. O que é whistle blower? Disponível em: http://enccla.camara.leg.br/noticias/oque-e-o-whistleblower. Acesso: out. 2019.

EUROPEAN COMISSION. Artificial Intelligence: A European Perspective. Disponível em: https://ec.europa.eu/jrc/en/publication/ artificial-intelligence-europeanperspective. Acesso: nov. 2019.
EVANGELISTA, Rafael et al. Dio: o mapeamento coletivo de câmeras de vigilância como visibilização da informatização do espaço urbano. In: BRUNO, Fernanda et al. (orgs.). Tecnopolíticas da vigilância. São Paulo: Boitempo, 2018.

FIGO, Anderson.Este gráfico mostra as 100 marcas mais valiosas do mundo em 2020. Disponível em: https://www.infomoney.com.br/consum o/este-grafico-mostra-as-100-marcasmais-valiosas-do-mundo-em-2020/.

Acesso: abr. 2020.

FOUCAULT, Michel. Em Defesa da Sociedade. São Paulo: Martins Fontes, 2010.

FOUCAULT, Michel. Vigiar e punir. nascimento da prisão. Petrópolis, RJ: Vozes, 1999.

G1. Entenda o caso de Edward Snowden, que revelou espionagem dos EUA. Disponível em: http://g1.globo.com/mundo/noticia/201 3/07/entenda-o-caso-de-edwardsnowden-que-revelou-espionagemdos-eua.html. Acesso: out. 2019.

GARRIDO, Óscar Gutiérrez; GRASSO, Daniele. China usa sua rede de embaixadas para estender o assédio à etnia uigur. Disponível em: https://brasil.elpais.com/brasil/2019/11/ 24/internacional/1574587269_365570. html. Acesso: nov. 2019.

GOVERNO POPULAR CENTRAL.Sobre a implementação de incentivos conjuntos para a prática da honestidade e confiabilidade: opiniões orientadoras sobre a aceleração da construção do sistema de crédito pessoal. Disponível em: http://www.gov.cn/hudong/201906/03/5397131/files/e3dc39de555f4fba a18e6fc3716550c3.pdf. Acesso: nov. 2019. 


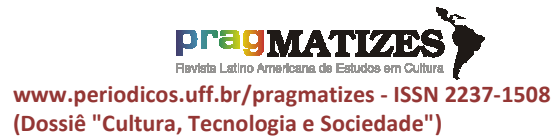

HAN, Byung-Chul. Sociedade do Cansaço. Petrópolis, RJ: Vozes, 2019.

HARRARI, Yuval. Homo Deus. Rio de Janeiro: Companhia das Letras, 2016.

HARRARI, Yuval. Uma breve história da humanidade. Porto Alegre: L\&PM Editores, 2016.

HBC CREDIT. Documento do Gabinete da Comissão Nacional de Desenvolvimento e Reforma (tradução livre). Disponível em: http://www.hbcredit.gov.cn/xyjs/tzgg/20 1608/P020160812332922961444.pdf. Acesso: nov. 2019.

HELDER. Os $5 \mathrm{Vs}$ do Big Data. Disponível em: https://culturaanalitica.com.br/os-5-vsbig-data. Acesso: out. 2019.

HORNBY, Lucy. China changes tack on 'social credit' scheme plan. Disponível em: https://www.ft.com/content/f772a9ce60c4-11e7-91a7-502f7ee26895. Acesso: out. 2019.

HOUSER, Kristin. Report: America Has a Social Credit System Much Like China's. Disponível em: https://futurism.com/america-socialcredit-system-china. Acesso: set. 2019.

INSTITUTO BRASILEIRO DE CIÊNCIAS CRIMINAIS. Nota técnica sobre Pacote Anticrime: comentários do Instituto Brasileiro de Ciências Criminais (IBCCRIM) sobre o Pacote Anticrime (PL 882/2019 e PL 1.864/2019). Disponível em: http://ibccrim.org.br/media/documentos /doc-31-03-2020-20-54-01-570213.pdf. Acesso: abr. 2020.

INSTITUTO BRASILEIRO DE GEOGRAFIA E ESTATÍSTICA. Projeção da população do Brasil e das Unidades da Federação. Disponível em:

https://www.ibge.gov.br/apps/populaca o/projecao/. Acesso: out. 2019.

KELSEN, Hans. Teoria Pura do Direito. São Paulo: Martins Fontes, 1999.

KISSINGER, Henry. Sobre a China. Rio de Janeiro: Objetiva, 2011.

LEWIS, Dev. All Carrots and No Sticks: A Case Study on Social Credit Scores in Xiamen and Fuzhou. Disponível em: https://medium.com/berkman-kleincenter/social-credit-case-study-citycitizen-scores-in-xiamen-and-fuzhou2a65feb2bbb3. Acesso: nov.2019.

MA, Alexandra. China reportedly made an app to show people if they're standing near someone in debt $-a$ new part of its intrusive 'social credit' policy. Disponível em: https://www.businessinsider.com/china -app-shows-map-of-people-in-debt-forsocial-credit-system-report-2019-1.

Acesso: nov. 2019.

MAIA, Roberta Mauro Medina. Vivendo nas nuvens: dados pessoais são objeto de propriedade? In: TEPEDINO, Gustavo; MENEZES, Joyceane Bezerra de (coord.). Autonomia privada, liberdade existencial e direitos fundamentais.Belo Horizonte: Fórum, 2019.

MARR, Bernard. Chinese Social Credit Score: Utopian Big Data Bliss Or Black Mirror On Steroids? Disponível em: https://www.forbes.com/sites/bernardm arr/2019/01/21/chinese-social-creditscore-utopian-big-data-bliss-or-blackmirror-on-steroids/\#66741c2148b8.

Acesso: out. 2019.

MATSAKIS, Louise. How the West Got China's Social Credit System Wrong. Disponível em: https://www. wired.com/story/china- 


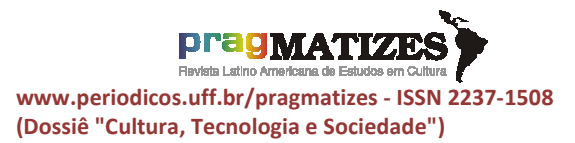

social-credit-score-system/. Acesso: out. 2019.

MATSUURA, Sérgio. Algoritmos reproduzem machismo e racismo por se basearem em práticas discriminatórias dos humanos. Disponível em: https://oglobo.globo.com/economia/alg oritmos-reproduzem-machismoracismo-por-se-basearem-em-praticasdiscriminatorias-dos-humanos24085081. Acesso: nov. 2019.

MCDONALD, Joe. China bars millions from travel for 'social credit' offenses. Disponível em: https://apnews.com/9d43f4b74260411 797043ddd391c13d8. Acesso: mar. 2020.

MEISSNER, Mirjam. China's Social Credit System: a big-data enabled approach to market regulation with broad implications for doing business in China. Disponível em: https://www.merics.org/sites/default/file s/2017-

09/China\%20Monitor_39_SOCS_EN.p df. Acesso: out. 2019.

MIGALHAS. STF: Associação de defensores públicos questiona dispositivos do pacote anticrime. Disponível em: https://www.migalhas.com.br/quentes/ 323707/stf-associacao-de-defensorespublicos-questiona-dispositivos-dopacote-anticrime. Acesso: abr. 2020.

MINISTÉRIO DA ECONOMIA. Cadastro base facilitará acesso dos cidadãos a serviços públicos federais. Disponível em: http://www.economia.gov.br/noticias/20 19/10/cadastro-base-facilitara-acessodos-cidadaos-a-servicos-publicosfederais. Acesso: nov. 2019.

MINISTÉRIO DA JUSTIÇA E SEGURANÇA PÚBLICA. Governo
Federal lança campanha publicitária do Pacote Anticrime. Disponível em: https://www.justica.gov.br/news/collecti ve-nitf-content-1570111509.73.

Acesso: nov. 2019.

MOSHER, Steve. China's new 'social credit system' is a dystopian nightmare. Disponível em: https://nypost.com/2019/05/18/chinasnew-social-credit-system-turns-orwells1984-into-reality/. Acesso: out. 2019.

MOZUR, Paul; ZHONG, Raymond; KROLIK, Aaron. In Coronavirus Fight, China Gives Citizens a Color Code, With Red Flags. Disponível em: https://www.nytimes.com/2020/03/01/b usiness/china-coronavirus-

surveillance.html. Acesso: mar. 2020.

MULHOLLAND, Caitlin. Mercado, pessoa humana e tecnologias: a Internet das coisas e a proteção do direito à privacidade. In: CORTIANO JR, Eroulths; EHRHARDT JR, Marcos; (orgs.). Transformações no Direito Privado nos 30 anos da Constituição: estudos em homenagem a Luiz Edson Fachin. Belo Horizonte: Forum, 2019.

MY NANJING. Disponível em: http://www.mynj.cn/. Acesso em: nov. 2019.

NATIONAL ENTERPRISE CREDIT INFORMATION PUBLICITY SYSTEM, Disponível em: http://www.gsxt.gov.cn/index.html. Acesso: nov. 2019.

O'NEIL, Cathy. Weapons of Math Destruction. Portland: Broadway Books, 2017.

ORENSTEIN, José. Por que o mundo nunca esteve tão bem, segundo dados deste pesquisador alemão. Disponível em:

https://www.nexojornal.com.br/express o/2017/05/29/Por-que-o-mundo-nuncaesteve-t\%C3\%A3o-bem-segundo- 


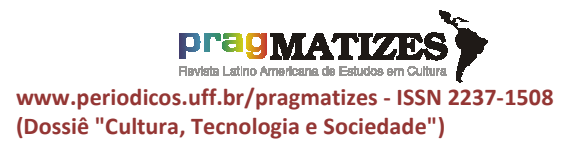

dados-deste-pesquisador-

alem\%C3\%A3o. Acesso: out. 2019.

ORWELL, George. 1984. Rio de Janeiro: Companhia das Letras, 2009.

PASQUALE, Frank. The Black Society: the secret algorithms that control money and information. Cambridge: Harvard University Press, 2015.

PEOPLE'S REPUBLIC OF CHINA. Main Functions of the NDRC. Disponível em: http://en.ndrc.gov.cn/. Acesso: outubro, 2019.

POHLMANN, Markus. George Orwell na China: digitalização como meio de controle social total. Disponível em: https://www.jota.info/opiniao-eanalise/artigos/george-orwell-na-chinadigitalizacao-como-meio-de-controlesocial-total-07102019. Acesso: out. 2019.

RAMZY, Austin; BUCKLEY, Chris. 'Absolutely No Mercy': Leaked Files Expose How China Organized Mass Detentions of Muslims. Disponível em: https://www.nytimes.com/interactive/20 19/11/16/world/asia/china-xinjiangdocuments.html. Acesso: nov. 2019.

REISINGER, Don. China Banned 23 Million People From Traveling Last Year for Poor 'Social Credit' Scores. Disponível em: https://fortune.com/2019/02/22/chinasocial-credit-travel-ban/. Acesso: mar. 2020.

RFI. China chega à fase final de sistema de avaliação de cidadãos $e$ preocupa Ocidente. Disponível em: http://www.rfi.fr/br/mundo/20200102em-2020-china-termina-de-testar-seusistema-de-cr\%C3\%A9ditos-sociais-eassusta-ocidente. Acesso: mar. 2020.

RODOTÀ, Stefano. $A$ vida na sociedade da vigilância: a privacidade hoje. [Organização, seleção e apresentação de Maria Celina Bodin de Moraes. Tradução: Danilo Doneda e Luciana Cabral Doneda] Rio de Janeiro: Renovar, 2008.

RODOTÀ, Stefano. Autodeterminação e laicidade. Revista Brasileira de Direito Civil - RBDCivil, Belo Horizonte, 2018. Disponível em: https://heinonline.org/HOL/LandingPag e?handle=hein.journals/rvbsdirec17\&di $\mathrm{v}=10 \& \mathrm{id}=$ \&page $=$. Acesso: out. 2019.

RODOTÀ, Stefano. Transformações do Corpo. Revista Trimestral de Direito Civil, Rio de Janeiro, vol. 19, jul.-set. 2004.

ROMANI, Bruno.Uso de dados de localização no combate à covid-19 pode ameaçar privacidade. Disponível em:

https://link.estadao.com.br/noticias/cult ura-digital,uso-de-dados-de-

localizacao-no-combate-a-covid-19pode-ameacar-

privacidade,70003268063. Acesso: abr. 2020.

SCHAEFER, Kendra. [Long read] The apps of China's social credit system. Disponível em: http://ub.triviumchina.com/2019/10/lon g-read-the-apps-of-chinas-socialcredit-system/. Acesso: out. 2019.

SENADO FEDERAL. Congresso conclui análise de vetos sobre proteção de dados. Disponível em: https://www12.senado.leg.br/noticias/m aterias/2019/10/02/congresso-concluianalise-de-vetos-sobre-protecao-dedados. Acesso: nov. 2019.

SENADO FEDERAL. Projeto de Lei $n^{\circ}$ 1179, de 2020. Disponível em: https://www25.senado.leg.br/web/ativid ade/materias/-/materia/141306.

Acesso: abr. 2020.

SHENG, Wei. One year after GDPR, China strengthens personal data 


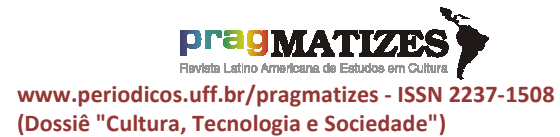

regulations, welcoming dedicated law. Disponível em: https://technode.com/2019/06/19/chindata-protections-law/. Acesso: nov. 2019.

SHIEL, Fergus; CHAVKIN, Sasha. China Cables: Who Are The Uighurs And Why Mass Detention? Disponível em:

https://www.icij.org/investigations/china -cables/china-cables-who-are-theuighurs-and-why-mass-detention/. Acesso: nov. 2019.

SNOWDEN, Edward. Eterna vigilância. São Paulo: Planeta, 2019.

SOCIAL CREDIT WATCH. What social credit isn't. Disponívelem: http://socialcredit.triviumchina.com/wha t-is-social-credit/what-social-creditisnt/. Acesso: nov. 2019.

SOLON, Olivia. Sorry, Y'AllHumanity's Nearingan Upgrade tolrrelevance. Disponível em: https://www.wired.com/2017/02/yuvalharari-tech-is-the-new-religion/.

Acesso: nov. 2019.

SOPRANA, Paula. PSDB, PSB, PSOL e OAB vão ao STF impedir repasse de dados de operadoras ao IBGE. Disponível em: https://www1.folha.uol.com.br/mercado /2020/04/psdb-psb-e-oab-vao-ao-stfimpedir-repasse-de-dados-deoperadoras-ao-ibge.shtml. Acesso: abr. 2020.

SOUZA, Carlos Affonso. Por que é um risco um cadastro com rosto, $R G$ e até nosso modo de andar. Disponível em: https://tecfront.blogosfera.uol.com.br/2 019/10/11/governo-cria-base-dedados-unificada-que-liga-cpf-rosto-eforma-de-andar/. Acesso: nov. 2019.

SOUZA, Jessica. Sistema de crédito social na China vai ser aplicado a empresas europeias. Disponível em: https://jornaleconomico.sapo.pt/noticia s/sistema-de-credito-social-na-chinavai-ser-aplicado-a-empresaseuropeias-483358. Acesso: set. 2019.

STEVESON, Alexandra; MOZUR, Paul. China Scores Businesses, and Low Grades Could Be a Trade-War Weapon. Disponível em: https://www.nytimes.com/2019/09/22/b usiness/china-social-credit-

business.html. Acesso: out. 2019.

STF. Ação Direta de Inconstitucionalidade: ADI 6387 MC / DF. Ministra relatora: Rosa Weber. DJ: 24/04/2020. Disponível em: http://portal.stf.jus.br/processos/detalh e. asp?incidente $=5895165$. Acesso: abr. 2020.

STF. Habeas Corpus. HC n83.096. Disponível em: http://portal.stf.jus.br/processos/detalh e.asp?incidente=2122576. Acesso: abr. 2020.

STF. Presidente do STF encontra presidente do Supremo Tribunal Popular da China. Disponível em: http://portal.stf.jus.br/noticias/verNotici aDetalhe.asp?idConteudo=113615\&ori =1. Acesso: out. 2019 .

STJ. Direito do Consumidor: Serviço e Proteção Ao Crédito - Súmula no 550. Disponível em: https://scon.stj.jus.br/SCON/sumanot/t oc.jsp?livre $=$ (sumula $\% 20$ adj $1 \% 20 \% 20$ 550).sub.\#TIT1TEMA0. Acesso: abr. 2020.

STJ. Recurso Especial: REsp 144008/RS. Terceira Turma. Relatora: Ministra Nancy Andrighi. DJ: 09/11/2016. Disponível em: https://ww2.stj.jus.br/processo/revista/i nteiroteor/?num_registro $=2014006464$ 60\&dt_publicacao=09/11/2016. Acesso: abr. 2020. 


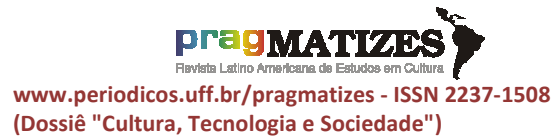

SUPREMO TRIBUNAL POPULAR DA CHINA. Rede aberta de informações executivas da China. Disponível em: http://zxgk.court.gov.cn/shixin/.

Acesso: nov. 2019.

TEPEDINO, Gustavo. Temas de Direito Civil. Rio de Janeiro: Renovar, 2009

THE CLIFFORD HUGH DOUGLAS INSTITUTE. What is social credit? Disponível em: https://www.socred.org/s-ctheory/what-is-social-credit. Acesso: nov. 2019.

THE ECONOMIST. Democracy Index 2015: Democracy in an age of anxiety. Disponível em: https://www.yabiladi.com/img/content/E IU-Democracy-Index-2015.pdf.

Acesso: nov. 2019.

THE SUPREME PEOPLE'S COURT OF THE PEOPLE'S REPUBLIC OF CHINA. Restricted consumption order. Disponível em: http://zxgk.court.gov.cn/shixin/restraini ngOrder.html. Acesso: nov. 2019.

TOCQUEVILLE, Alexis de. $A$ democracia na América. São Paulo: Martins Fontes, 2005.

WANG, Xian. Entrevista concedida a Pedro Teixeira Gueiros. Rio de Janeiro, novembro, 2019.

WIKILEAKS. What is Wikileaks. Disponível em: https://wikileaks.org/What-is-

WikiLeaks.html. Acesso: out. 2019.

WIRED. China is using coronavirus to boost its dystopian social credit system. Disponível em: https://www.wired.co.uk/article/chinasocial-credit-coronavirus. Acesso: mar. 2020.

WITHNALL, Adam. UK government urged to ban import of Chinese cotton 'made using Uighur Muslim forced labour'. Disponível em: https://www.independent.co.uk/news/u $\mathrm{k} /$ home-news/chinese-cotton-ukgovernment-important-uighur-muslimlabour-a9478501.html. Acesso: abr. 2020.

XIAMEN BIG DATA INDUSTRY SERVICE PLATFORM. What is the social credit system? Disponível em: http://www.xmdata.com.cn/. Acesso: nov. 2019.

XINHUA.Tribunais chineses impedem mais de 14,5 milhões de inadimplentes (Tradução livre). Disponível em: http://www.xinhuanet.com/english/2019 -07/11/c 138217837.htm. Acesso: nov. 2019.

XINHUANET. Alipay health code landed in 100 cities in 7 days, digital epidemic prevention ran out of "Chinese speed". Disponível em: http://www.xinhuanet.com/tech/202002/19/c_1125596647.htm. Acesso: abr. 2020. 